\title{
Tracing ancient hydrogeological fracture network age and compartmentalisation using noble gases
}

DOI:

10.1016/j.gca.2017.10.022

\section{Document Version}

Accepted author manuscript

Link to publication record in Manchester Research Explorer

\section{Citation for published version (APA):}

Warr, O., Lollar, B. S., Fellowes, J., Sutcliffe, C. N., McDermott, J. M., Holland, G., Mabry, J. C., \& Ballentine, C. J. (2017). Tracing ancient hydrogeological fracture network age and compartmentalisation using noble gases. Geochimica et Cosmochimica Acta, 222, 340-362. https://doi.org/10.1016/j.gca.2017.10.022

\section{Published in:}

Geochimica et Cosmochimica Acta

\section{Citing this paper}

Please note that where the full-text provided on Manchester Research Explorer is the Author Accepted Manuscript or Proof version this may differ from the final Published version. If citing, it is advised that you check and use the publisher's definitive version.

\section{General rights}

Copyright and moral rights for the publications made accessible in the Research Explorer are retained by the authors and/or other copyright owners and it is a condition of accessing publications that users recognise and abide by the legal requirements associated with these rights.

\section{Takedown policy}

If you believe that this document breaches copyright please refer to the University of Manchester's Takedown Procedures [http://man.ac.uk/04Y6Bo] or contact uml.scholarlycommunications@manchester.ac.uk providing relevant details, so we can investigate your claim.

\section{OPEN ACCESS}




\section{Accepted Manuscript}

Tracing ancient hydrogeological fracture network age and compartmentalisation using noble gases

Oliver Warr, Barbara Sherwood Lollar, Jonathan Fellowes, Chelsea N. Sutcliffe, Jill M. McDermott, Greg Holland, Jennifer C. Mabry, Christopher J. Ballentine

PII: S0016-7037(17)30685-3

DOI: https://doi.org/10.1016/j.gca.2017.10.022

Reference: GCA 10527

To appear in:

Geochimica et Cosmochimica Acta

Received Date:

3 March 2017

Accepted Date: 16 October 2017

Please cite this article as: Warr, O., Sherwood Lollar, B., Fellowes, J., Sutcliffe, C.N., McDermott, J.M., Holland, G., Mabry, J.C., Ballentine, C.J., Tracing ancient hydrogeological fracture network age and compartmentalisation using noble gases, Geochimica et Cosmochimica Acta (2017), doi: https://doi.org/10.1016/j.gca.2017.10.022

This is a PDF file of an unedited manuscript that has been accepted for publication. As a service to our customers we are providing this early version of the manuscript. The manuscript will undergo copyediting, typesetting, and review of the resulting proof before it is published in its final form. Please note that during the production process errors may be discovered which could affect the content, and all legal disclaimers that apply to the journal pertain. 
Tracing ancient hydrogeological fracture network age and compartmentalisation using noble gases

Authors: ${ }^{1,2}$ Oliver Warr (corresponding author), ${ }^{2}$ Barbara Sherwood Lollar, ${ }^{3}$ Jonathan Fellowes, ${ }^{2}$ Chelsea N. Sutcliffe, ${ }^{2}$ Jill M. McDermott, ${ }^{3}$ Greg Holland, ${ }^{1}$ Jennifer C. Mabry \& ${ }^{1}$ Christopher J. Ballentine

${ }^{1}$ Department of Earth Sciences, University of Oxford, South Parks Road, Oxford, OX1 3AN, United Kingdom. Email: oliver.warr@utoronto.ca, phone: +1 4169783022

${ }^{2}$ Department of Earth Sciences, University of Toronto, Toronto, Ontario, Canada.

${ }^{3}$ School of Earth, Atmospheric and Environmental Sciences, Williamson Building,

University of Manchester, Manchester, M13 9PL, United Kingdom. 


\section{Abstract}

We show that fluid volumes residing within the Precambrian crystalline basement account for ca $30 \%$ of the total groundwater inventory of the Earth $\left(>30\right.$ million $\left.\mathrm{km}^{3}\right)$. The residence times and scientific importance of this groundwater are only now receiving attention with ancient fracture fluids identified in Canada and South Africa showing: 1. microbial life which has existed in isolation for millions of years; 2. significant hydrogen and hydrocarbon production via waterrock reactions; and 3. preserving noble gas components from the early atmosphere. Noble gas ( $\mathrm{He}, \mathrm{Ne}, \mathrm{Ar}, \mathrm{Kr}, \mathrm{Xe}$ ) abundance and isotopic compositions provide the primary evidence for fluid mean residence time (MRT). Here we extend the noble gas data from the Kidd Creek Mine in Timmins Ontario Canada, a volcanogenic massive sulfide (VMS) deposit formed at $2.7 \mathrm{Ga}$, in which fracture fluids with MRTs of 1.1-1.7 Ga were identified at 2.4km depth (Holland et al., 2013); to fracture fluids at $2.9 \mathrm{~km}$ depth. We compare here the Kidd Creek Mine study with noble gas compositions determined in fracture fluids taken from two mines (Mine $1 \&$ Mine 2) at 1.7 and $1.4 \mathrm{~km}$ depth below surface in the Sudbury Basin formed by a meteorite impact at $1.849 \mathrm{Ga}$.

The $2.9 \mathrm{~km}$ samples at Kidd Creek Mine show the highest radiogenic isotopic ratios observed to date in free fluids (e.g. ${ }^{21} \mathrm{Ne} /{ }^{22} \mathrm{Ne}=0.6$ and ${ }^{40} \mathrm{Ar} /{ }^{36} \mathrm{Ar}=102,000$ ) and have MRTs of 1.0 to 2.2 Ga. In contrast, resampled $2.4 \mathrm{~km}$ fluids indicated a less ancient MRT (0.2-0.6 Ga) compared with the previous study (1.1-1.7 Ga). This is consistent with a change in the age distribution of fluids feeding the fractures as they drain, with a decreasing proportion of the most ancient endmember fluids. ${ }^{129} \mathrm{Xe} /{ }^{136} \mathrm{Xe}$ ratios for these fluids confirm that boreholes at $2.4 \mathrm{~km}$ versus $2.9 \mathrm{~km}$ are sourced from hydrogeologically distinct systems. In contrast, results for the Sudbury mines 
have MRTs of 0.2-0.6 and 0.2-0.9 Ga for Mines 1 and 2 respectively. While still old compared to almost all groundwaters reported in the literature to date, these younger residence times compared to Kidd Creek Mine are consistent with significant fracturing created by the impact event, facilitating more hydrogeologic connection and mixing of fluids in the basin. In all samples from both Kidd Creek Mine and Sudbury, a ${ }^{124-128}$ Xe excess is identified over modern air values. This is attributed to an early atmospheric xenon component, previously identified at Kidd Creek Mine but which has to date not been observed in fluids with a residence time as recent as $0.2-0.6 \mathrm{Ga}$. The temporal and spatial sampling at Kidd Creek Mine is also used to verify our proposed conceptual model which provides key constraints regarding distribution, volumes and residence times of fracture fluids on the smaller, regional, scale.

\section{Introduction}

Brines rich in helium, hydrogen, methane and nitrogen within Precambrian crustal rocks have been shown to provide habitable environments for subsurface microbial life (Chivian et al., 2008; Lin et al., 2006; Lau et al., 2016; Magnabosco et al., 2016). The global significance of such ancient rocks for sustaining subsurface life has recently been demonstrated through the identification of water-rock reactions producing electron donors (e.g. hydrogen; Sherwood Lollar

et al., 2014) and electron acceptors (e.g. dissolved sulfate; Li at al., 2016). Recent studies have also shown there is significant methanogenesis in these fracture waters, via both microbial methanogenesis, and abiotic water-rock interactions such as Fischer-Tropsch synthesis (Sherwood Lollar et al., 2002; Sherwood Lollar et al., 2006; Kietäväinen and Purkamo, 2015). The significance of these Precambrian crustal systems in global hydrogen production and deep 
carbon cycles has only recently been investigated (Sherwood Lollar and Ballentine, 2009; Etiope and Sherwood Lollar, 2013; Sherwood Lollar et al., 2014). Given the long residence times of some of these fracture fluids (> 1 Ga Holland et al., 2013; Lippmann-Pipke et al., 2011), and the discovery of ancient components of other elements (e.g. Archean atmospheric derived xenon Holland et al., 2013; mass independent sulfur isotope signatures; Li et al., 2016), it is reasonable to expect these types of system may have affected global cycles over geological and planetary timescales. The exploration for microbial life (Pedersen et al., 2005; Lin et al., 2006; Chivian et al., 2008), in these ancient terrestrial rocks focuses on developing an understanding of the distribution of biomass and biodiversity, which when coupled with a quantitative estimate of the mean residence times of the fluids within which life is found may provide insights into the evolution and distribution of microbial life over the course of the Earth's history (Sherwood Lollar and Ballentine, 2009; Onstott et al., 2010; Kietäväinen and Purkamo, 2015).

To advance this new area of research, the distribution of residence times of the fluids within different regions of the $>70 \%$ of the continental lithosphere that is Precambrian in age is required. This information will address the compartmentalization of the deep hydrogeosphere the degree of hydrogeological connection between different fracture fluid systems, and/or their degree of isolation from each other and the surface hydrosphere. The unique properties of noble gases can be applied to constrain these variables (Holland et al., 2013; Lippmann-Pipke et al., 2011; Sherwood Lollar and Ballentine, 2009).

The Kidd Creek Mine deposit in the Superior Province of the Canadian Shield is the site where previous noble gas analysis of fluid samples rich in helium, hydrogen, methane and nitrogen collected at $2.4 \mathrm{~km}$ depth from a copper-zinc mine in Timmins, Ontario, identified the oldest isolated fracture fluids, with a mean residence time range of 1.1 - 1.7 Ga (Holland et al., 2013). 
This age was based on a radiogenic excess of ${ }^{4} \mathrm{He},{ }^{21} \mathrm{Ne},{ }^{40} \mathrm{Ar}$ and ${ }^{136} \mathrm{Xe}$, a preserved early atmospheric ${ }^{124-128} \mathrm{Xe}$ signal and a sedimentary-derived ${ }^{129} \mathrm{Xe}$ excess (assumed to be from a localised sedimentary source). This study documented fluids with the longest mean residence times ever observed in the crust to date, and showed that fracture fluids in these Precambrian systems could be isolated on planetary timescales. Since this study the Kidd Creek Mine has been expanded to an even deeper level $(2.9 \mathrm{~km})$. The three main objectives of this study were 1 . to resample the fracture fluids identified by Holland et al. (2013) in to order to test the hypothesis that in the 44 months since the previous study the mean residence time would decrease due to draining of fractures (See Section 5.2 \& Figure 7); 2. to sample the new deeper levels of the Kidd Creek Mine site to understand the distribution of ancient fluids; and 3. to compare and contrast the fluids from Kidd Creek Mine to those of two new sites in the Sudbury Basin. The two Sudbury mines are situated in 2.6-2.7 Ga Archean bedrock underlying the Sudbury Igneous Complex, a 1.849 Ga formation produced by a bolide impact (Krogh et al., 1984; Card, 1994; Davis, 2008). The impact produced major fracturing of the bedrock and hence likely opened significantly more lines of structural weakness along which fluid movement and mixing could occur compared to the relatively less disturbed geologic setting at Kidd Creek Mine.

\section{Geological Background}

2.1 Geology of the Superior Province of the Canadian Shield - Kidd Creek Mine, near Timmins, Ontario, Canada 
Kidd Creek Mine, Timmins, Ontario (Figure 1) is situated $24 \mathrm{~km}$ north of the town of Timmins, within a stratiform Volcanogenic Massive Sulphide (VMS) deposit of 2.7 Ga age (Thurston et al., 2008). This deposit lies within the Kidd-Munro assemblage of the Southern Volcanic Zone of the Abitibi greenstone belt of the Superior Province of the Canadian Shield (Bleeker and Parrish, 1996). The Kidd-Munro assemblage itself consists of a series of steeply dipping interlayered felsic, mafic, ultramafic and metasedimentary deposits. One of the primary economic resources, the stringer ore, is predominantly associated with the upper felsic region and formed as a result of silica and metal-rich hydrothermal fluid circulation below the seafloor. Above the stringer ore deposits lie banded and massive sulphide ores. These are considered to have been initially deposited as inorganic precipitates formed where hydrothermal solutions rich in metals entered the seawater. Intermittent argillite to chert carbonaceous horizons within the assemblage represent periods of volcanic quiescence during which proximal seafloor sediments accumulated. Following deposition of the Kidd-Munro assemblage, the entire formation was metamorphosed to greenschist facies during the last major regional metamorphic event at 2.67-2.69 Ga. The last known episode of metasomatism occurred at 2.64 Ga (Davis et al., 1994; Bleeker and Parrish, 1996; Thurston et al., 2008; Berger et al., 2011).

Kidd Creek Mine was opened in 1964 as an open pit. Since then it has been developed vertically to a depth of $2.9 \mathrm{~km}$. In this facility, mining involves lateral coring via multiple boreholes at each level as described in detail in Li et al. (2016). Exploration boreholes frequently intersect pockets of fracture fluids trapped within the host rock. Once pierced, fluids from these pockets have been observed to flow over prolonged time periods, in some cases $>7$ years since first discovered by 
our team. Gas samples taken from these fracture fluids were analyzed for their noble gas content, following the methods of Ward et al. (2004) and Holland et al. (2013).

\subsection{Geology of the Sudbury Basin and underlying Archean basement, near Sudbury, Ontario, Canada}

The Sudbury Basin is located approximately $300 \mathrm{~km}$ south-east of Kidd Creek Mine (Figure 1). The Sudbury Impact Complex (SIC) formed at $1.849 \mathrm{Ga}$ by an estimated 10-15 km diameter meteorite impacting the Archean basement (consisting of carbonaceous shale, metavolcanic and metasedimentary rocks, gneisses \& related intrusive rocks, primarily 2.6-2.7 Ga in age, Card, 1994; Meldrum et al., 1997; Davis, 2008). The resulting impact-induced melting and differentiation formed noritic to gabbroic cumulates overlain by residual granophyres (Pattison, 2009). Magmatic sulphide deposits at the base of the SIC contact, along with associated dykes and breccia in the footwall together, form one of the world's largest nickel, copper, platinum, and palladium economic resources exploited by multiple mining operations (Long, 2009). The region has been deformed by three main major orogenic events: the Penokean (1.89-1.830 Ga); the Mazatzal (1.7-1.6 Ga) and the Grenville (1.4-1.0 Ga). Most recently the North-Eastern section of the Sudbury structure was deformed by yet another impactor forming Lake Wanapitei (37 Ma). The basin and underlying Archean basement rocks have been heavily faulted and folded and metamorphosed up to granulite facies between 2.6-2.7 Ga and more recently amphibolite facies at 1.9-1.8 Ga (James and Golightly, 2009 and references therein).

Both Sudbury mines sampled in this study are located in the footwall of the basin, hosted in 2.6-

2.7 Ga Levack Gneiss Archean basement. The first mine (Mine 1) is at $1.7 \mathrm{~km}$ depth and the 
second mine (Mine 2) is at $1.4 \mathrm{~km}$ depth. Both Mine 1 and Mine 2 are nickel-copper mines and are located in the northeast and northwest region of the Sudbury Impact Complex, approximately $25 \& 33 \mathrm{~km}$ from the City of Sudbury respectively. Mine 1 has been in operation since 2006 and Mine 2 since 1984. As with Kidd Creek Mine, isolated pockets of fracture fluids within the host rock were accessed via lateral boreholes.

\subsection{Sample Collection}

All samples were collected at the borehole collars from which fluids (and dissolved gases) were naturally flowing (Table 1) (see Holland et al., 2013 and Li et al., 216 for detailed description). Briefly, as in previous studies, an inflatable packer was inserted into the borehole opening to prevent any atmospheric contamination (e.g. Holland et al., 2013; Sherwood Lollar et al., 2002; Ward et al., 2004). Fluids from each borehole were allowed to separate into gas and water phases by flowing through a gas stripper. Gas samples from fracture fluids were collected in refrigeration-grade, internally polished, 3/8" diameter copper tubes used routinely in noble gas studies. Prior to sample collection, any air contamination was flushed out of the sampling apparatus and copper tubes by flowing borehole fluids through the equipment for a minimum of 20 minutes (as a function of the flowrates and volume of the sampling apparatus). Once flushing to remove air contamination was complete and a representative sample of the fracture fluids established, the copper tubes were cold-welded shut using a hydraulic crimping device. Samples were collected from Kidd Creek Mine at $2.4 \mathrm{~km}$ and $2.9 \mathrm{~km}$ depth and from Sudbury Mines 1 and 2 at 1.7 and $1.4 \mathrm{~km}$ depth respectively. As noted, the sample at $2.4 \mathrm{~km}$ were samples from 
the same boreholes reported by Holland et al. (2013). For the samples at $2.9 \mathrm{~km}$, due to mine operations, no water samples could be collected (standing water only in the boreholes with no artesian flow in this case), but gas samples were collected using the same methodology as above.

\section{Sample Analysis}

Samples were analyzed using a combined dual mass spectrometer and purification system in the Noble Laboratory at the Department of Earth Sciences, University of Oxford (Barry et al., 2016). Samples were mounted on to the purification system by clamping the copper tubes adjacent to the cold weld using standard clamping procedures, removing the cold weld, and connecting to the line using a stainless-steel tube fitting to form a metal on metal seal. Ultra-High Vacuum (UHV) was reached using a combination of roughing and turbo pumps. Prior to sample analysis the integrity of the metal seal for each mounted sample was verified via standard helium leak testing (e.g. Warr et al., 2015).

\subsection{Separation of noble gases}

Given the extremely radiogenic nature of these samples, efficient separation of helium from neon and argon from krypton and xenon was essential. This was achieved through a process of repeat cycling of the respective traps, and static or dynamic pumping for $\mathrm{He} / \mathrm{Ne}$ and $\mathrm{Ar} / \mathrm{Kr}$ and $\mathrm{Ar} / \mathrm{Xe}$ respectively. In all cases separation with no loss or fractionation was verified using procedural air calibrations which were analyzed using the same protocols. Removal of helium was confirmed via the Helix SFT prior to neon release, and argon separation was verified via measurement post-Kr and $\mathrm{Xe}$ analysis. In both cases, residual helium and argon analyzed during 
the neon and the krypton/xenon analyses respectively were estimated to be $<0.005 \%$ of their original intensities and have no pressure effect on the neon or krypton/xenon measurements.

\subsection{Analytical procedure}

Initially samples and procedural standards were expanded to a known volume fitted with a 1000 Torr Baratron, and the pressure and temperature of the sample was recorded. Next the sample was exposed to approximately $30 \mathrm{~g}$ of activated titanium sponge held at $1223 \mathrm{~K}\left(950{ }^{\circ} \mathrm{C}\right)$ to chemically remove the majority of the active gases. After 30 minutes the sponge was allowed to cool for a further 30 minutes to allow removal of $\mathrm{H}_{2}$ (Stout and Gibbons, 1955). The sample was further purified for an additional 15 minutes using a combination of a hot (SAES GP-50) and cold (SAES NP-10) getters. The cleaned gas was then passed through a series of helium-cooled calibrated cryogenic traps to 1 . remove water vapour (stainless steel, $180 \mathrm{~K}$ ) 2. trap argon, krypton and xenon (stainless steel, $33 \mathrm{~K}$ ) and 3. trap helium and neon (charcoal, $15 \mathrm{~K}$ ). Each trapping stage lasted 15 minutes (Barry et al., 2016).

For helium analysis, the charcoal trap was heated to $31 \mathrm{~K}$ for 15 minutes, split using known volume expansions and then measured using a HELIX SFT. Peak centres were defined manually

and ${ }^{3} \mathrm{He}$ and ${ }^{4} \mathrm{He}$ were measured simultaneously on an electron multiplier and on a Faraday respectively.

In order to measure neon, it was necessary to first remove any residual helium from the system. This was efficiently achieved by developing a technique for these highly radiogenic samples which cycled the charcoal trap to $50 \mathrm{~K}$ for 15 minutes then back down to $31 \mathrm{~K}$ for a further 15 
minutes. This allowed any potential trace helium $(<<1 \%)$ still adsorbed to the charcoal as well as residual helium in the headspace, to be released while trapping all neon. The gas was then expanded to the manifold and pumped, during which the charcoal trap was isolated. This nondynamic heating, cooling and pumping process was repeated two further times.

Next, following the methods of Barry et al. (2016), the charcoal trap was heated to $90 \mathrm{~K}$ for 15 minutes to release all neon and a known volume was inlet into the ARGUS VI for measurement. Each analysis consisted of peak-jumping in which ${ }^{20} \mathrm{Ne}$ and ${ }^{22} \mathrm{Ne}$ were measured on Faraday cups and ${ }^{21} \mathrm{Ne}$ was measured on a multiplier. Additionally, during each cycle, ${ }^{40} \mathrm{Ar}$ and $\mathrm{CO}_{2}$ were measured to allow correction for ${ }^{40} \mathrm{Ar}^{++}$and $\mathrm{CO}_{2}^{++}$interference peaks. Following the measurement, the charcoal trap was heated to $300 \mathrm{~K}$, opened to the vacuum pump to remove any remaining sample, and then isolated from the line.

For argon measurements, the stainless-steel trap was heated to $200 \mathrm{~K}$ for 15 minutes to release all noble gases; from which a small aliquot is taken. Once this aliquot was taken the trap was cooled back down to $52 \mathrm{~K}$ to re-trap the heavy noble gases. The aliquot was expanded and diluted using calibrated volumes to reduce the ${ }^{40} \mathrm{Ar}$ to measurable levels. The gas was then inlet to the ARGUS VI which measured ${ }^{36} \mathrm{Ar}$ and ${ }^{38} \mathrm{Ar}$ on an electron multiplier and ${ }^{40} \mathrm{Ar}$ on a Faraday cup via peak-jumping.

In order to measure krypton and xenon it was necessary to isolate and remove the residual argon. This was accomplished through a series of trap cycling and pumping steps specifically developed for these highly radiogenic samples. Here the stainless-steel trap was cycled from $52 \mathrm{~K}$ to $70 \mathrm{~K}$, to release Ar, then back down to $52 \mathrm{~K}$, waiting 15 minutes to allow full re-trapping of $\mathrm{Kr}$ and $\mathrm{Xe}$ then 5 minutes dynamic pumping to remove the argon. After 5 cycles the stainless-steel trap was 
heated to $200 \mathrm{~K}$ to ensure release of all noble gases. The sample was then inlet into the ARGUS where all krypton and xenon isotopes were measured in one analysis using peak jumping. During this measurement ${ }^{78} \mathrm{Kr}$, ${ }^{124} \mathrm{Xe}$ and ${ }^{126} \mathrm{Xe}$ were measured on the electron multiplier and the remaining isotopes were measured using Faraday cups.

\subsection{Standards and line blanks}

At the beginning of the sample suite a full procedural air standard was run from an air cylinder which was collected 24.11.14 in University Parks, Oxford, UK. This standard was collected under known environmental conditions $\left(5^{\circ} \mathrm{C}, 89 \%\right.$ humidity and $1027 \mathrm{mBar}$ pressure $)$ as per standard procedures for noble gas analysis (Warr et al., 2015; Barry et al., 2016)). For comparison between sample and standard the pressure was measured using the 1000 Torr Baratron over the same volume used for sample inlet. Analysis of the air standard followed the same procedure as the samples. Additionally, a full procedural system blank using the sample protocol was also run mid-way through the sample suite to provide a measure of background for subtraction. To factor in any day-to day changes in mass spectrometer sensitivity, and confirm reproducibility, a separate and fully automated standard was analysed, usually overnight, in between samples, procedural blanks and procedural air standards.

All analytical errors were propagated using the standard addition in quadrature method (e.g.

Warr et al., 2015). Where averages are used (e.g. for each mine level Tables 2-5) the error is taken as the standard deviation of individual data points, which is always comparable to, or greater than, analytical uncertainty for the individual data points.

\section{Results}


All ratios and concentrations of representative isotopes are presented respectively in Tables 2-6.

\subsection{Concentrations of noble gases}

In geological systems where water-rock reactions have been shown to produce significant concentrations of reactive gases such as $\mathrm{H}_{2}$, methane, and other hydrocarbon gases (Sherwood Lollar et al., 2002; Sherwood Lollar et al., 2014), absolute concentrations of conservative noble gases per $\mathrm{cm}^{3}$ of gas (Table 2) are of limited utility. This is because noble gas concentrations within the gas phase may have been affected by both in situ $\mathrm{H}_{2}$ and $\mathrm{CH}_{4}$ production and addition, and loss of reactive gases through other sinks in the subsurface (e.g. water rock interactions, or microbial uptake). As a result of these processes noble gas concentrations within the gas phase can become passively enriched or diluted. However, initial concentrations within the fracture fluids can be reconstructed using non-radiogenic isotopes coupled with measured isotopic ratios after the method of Holland et al., 2013. This method assumes that the ${ }^{36} \mathrm{Ar}$ in the sampled gas is entirely derived from water that equilibrated with the atmosphere. Here we take seawater at 10 ${ }^{\circ} \mathrm{C}$ as our initial ${ }^{36} \mathrm{Ar}$ composition (Kipfer et al., 2002) following the arguments of Holland et al (2013). The ${ }^{36}$ Ar concentration measured in the gas phase then allows calculation of the volume of water required to completely degas to provide that amount of ${ }^{36} \mathrm{Ar}$ (e.g. Ballentine et al., 1991; Ballentine et al., 2002), thereby allowing calculation of the total gas/water ratio for the concentration of each individual species within this nominal associated water mass. Selected radiogenic and non-radiogenic noble gas isotopes are given as concentrations within the nominal

associated water mass and presented as concentrations in $\mathrm{cm}^{3}$ per $\mathrm{cm}^{3}$ of fracture fluid at STP 
conditions (Table 3, 4). Values for all isotopes are additionally provided in Appendix A. These are the concentrations which are discussed in the remainder of this section.

\subsection{Concentrations of air-saturated components}

Through normalising non-radiogenic isotopes (Table 3 ) to a single isotope $\left({ }^{36} \mathrm{Ar}\right.$ ) it is possible to compare elemental ratios in samples with elemental ratios in air-saturated seawater at $10{ }^{\circ} \mathrm{C}$, in order to identify any elemental fractionation within each system and assess how reasonable the inferred starting composition is. This is presented in Figure 2.

Partial degassing of fluids with an initial ASW concentration via open Rayleigh degassing would result in a gas composition enriched in ${ }^{20} \mathrm{Ne}$ and depleted in ${ }^{84} \mathrm{Kr}$ and ${ }^{130} \mathrm{Xe}$ relative to ${ }^{36} \mathrm{Ar}$. This observation does not match observed ratios for the resampled boreholes from $2.4 \mathrm{~km}$ at Kidd Creek Mine, nor samples from Mines $1 \& 2$. Hence no major fractionation related to degassing is inferred for ${ }^{20} \mathrm{Ne},{ }^{84} \mathrm{Kr}$ or ${ }^{130} \mathrm{Xe}$ for these samples. This lack of observable solubility-dependent loss/gain outside of uncertainty suggests that near complete degassing of the original fluid phase has occurred. Hence the data for these samples do not require any post-processing to account for only partial degassing of the fracture fluid. Small deviations from expected elemental ratios are likely due to the large current uncertainty in initial temperature and salinity from the assumed starting conditions (seawater at $10^{\circ} \mathrm{C}$ ), both of which can have an effect on noble gas solubility (Crovetto et al., 1982; Smith, 1985; Smith and Kennedy, 1983).

In contrast, in the case of Kidd Creek Mine samples from $2.9 \mathrm{~km}$ depth, there is evidence for Rayleigh fractionation on a localised borehole scale (Appendix C) which has created an enrichment of ${ }^{20} \mathrm{Ne}$ coupled with a deficit of ${ }^{84} \mathrm{Kr}$ and ${ }^{130} \mathrm{Xe}$ relative to ${ }^{36} \mathrm{Ar}$. With ${ }^{36} \mathrm{Ar}$ values 
depleted by $17 \%$ from the assumed starting conditions. A correction for this has been applied to each noble gas $(30.6 \%, 29.6 \%, 17.0 \%, 11.4 \%, \& 8.4 \%$ for helium - xenon respectively) based on their respective solubilities and the recalculated radiogenic excesses for each noble gas are presented in Table 7. These are the values referred to when discussing radiogenic concentrations and the residence time calculations in Section 4.10. A comprehensive discussion and quantification of the degassing is provided in Appendix C.

\subsection{Helium}

In all samples in this study, the ${ }^{3} \mathrm{He} /{ }^{4} \mathrm{He}$ ratios are consistent with typical crustal radiogenic production rates estimated for crystalline rock globally (Ballentine and Burnard, 2002). Consistent with previous work in these tectonically quiescent environments, no mantle component is observed (Sherwood Lollar et al., 1993; Lippmann-Pipke et al., 2011; Holland et al., 2013). The ${ }^{3} \mathrm{He} /{ }^{4} \mathrm{He}$ ratios for all samples are given in Table 5. As per convention these ratios are given in $\mathrm{R}_{\mathrm{A}}$ where $1 \mathrm{R}_{\mathrm{A}}$ is the atmospheric ratio $\left(1.4 \times 10^{-6}\right)$. All helium ratios are highly radiogenic $(<0.026 \mathrm{Ra})$. This is reinforced by the absolute average concentrations of ${ }^{4} \mathrm{He}$ per $\mathrm{cm}^{3}$ of fracture fluid which in Kidd Creek Mine range between 0.08 (at $2.4 \mathrm{~km}$ ) and $0.36 \mathrm{~cm}^{3}$ ${ }^{4} \mathrm{He}$ per $\mathrm{cm}^{3}$ of fracture fluid (at $2.9 \mathrm{~km}$ ) and 0.06 and $0.03 \mathrm{~cm}^{3}{ }^{4} \mathrm{He}$ per $\mathrm{cm}^{3}$ of fracture fluid in Mine 1 (at $1.7 \mathrm{~km}$ ) and Mine 2 (at $1.4 \mathrm{~km}$ ) respectively for the Sudbury system. These concentrations are at least six orders of magnitude greater than the initial ASW concentration (Kipfer et al., 2002). Consequently, any air-derived component present is negligible and no corrections need to be applied. 


\subsection{Neon}

For all samples, isotopic ratios of ${ }^{21} \mathrm{Ne} /{ }^{20} \mathrm{Ne}$ and ${ }^{22} \mathrm{Ne} /{ }^{20} \mathrm{Ne}$ are greater than $\mathrm{ASW}$ due to a resolvable excess of radiogenic ${ }^{21} \mathrm{Ne}$ and ${ }^{22} \mathrm{Ne}$. In the resampled fracture fluids from $2.4 \mathrm{~km}$ at Kidd Creek Mine, average ${ }^{21} \mathrm{Ne}$ excesses are $3.2 \times 10^{-9} \mathrm{~cm}^{3}{ }^{21} \mathrm{Ne}$ per $\mathrm{cm}^{3}$ of fracture fluid. Greater average excesses over an ASW starting composition are observed in the deeper $2.9 \mathrm{~km}$ level samples $\left(1.6 \times 10^{-8} \mathrm{~cm}^{3}{ }^{21} \mathrm{Ne}\right.$ per $\mathrm{cm}^{3}$ of fracture fluid) which, like helium, indicates the deeper level contains a larger radiogenic excess. In the Sudbury samples, average radiogenic neon excesses are smaller overall, with Mines 1 and 2 having a ${ }^{21} \mathrm{Ne}$ excess of $1.8 \times 10^{-9}$ and 1.2 $\times 10^{-9} \mathrm{~cm}^{321} \mathrm{Ne}$ per $\mathrm{cm}^{3}$ of fracture fluid respectively.

The measured isotopes of neon from Table 4 are presented graphically in Figure 3.

As seen in Figure 3, samples from Kidd Creek Mine at the deeper level (2.9 km) are even more displaced from initial air ratios (ASW) relative to their $2.4 \mathrm{~km}$ counterparts. Indeed, the ${ }^{21} \mathrm{Ne} /{ }^{22} \mathrm{Ne}$ ratios for the $2.9 \mathrm{~km}$ samples are the highest ever measured in crustal samples, free fluids or otherwise (Lippmann-Pipke et al., 2011). As was seen in Holland et al. (2013), the data from this study indicate that fracture fluids in these Precambrian crystalline systems are characterised by a radiogenic ${ }^{20} \mathrm{Ne} /{ }^{22} \mathrm{Ne}$ end-member that is significantly elevated (red line) compared to what had previously been expected for crystalline rock (black line, Kennedy et al., 1990; Ballentine and Burnard, 2002). The new samples from 2.4 km depth at Kidd Creek Mine (black squares) similarly preserve an elevated crustal production of neon, however, they have somewhat lower ${ }^{21} \mathrm{Ne} /{ }^{20} \mathrm{Ne}$ and ${ }^{22} \mathrm{Ne} /{ }^{20} \mathrm{Ne}$ ratios compared to the 2013 study (blue squares) when they were first sampled $>7$ years ago. Only the data for Mine 2 from Sudbury lie close to the traditional ASW-crustal mixing line (black line), as did one sample from the Holland et al. 
(2013) study. The implications of this data for neon production rate are discussed in Section 5.55 .

\subsection{Argon}

Concentrations of ${ }^{40} \mathrm{Ar}$ are also elevated in all fluid systems due to radiogenic decay of ${ }^{40} \mathrm{~K}$, with concentrations as high as $0.10 \mathrm{~cm}^{3}{ }^{40} \mathrm{Ar}$ per $\mathrm{cm}^{3}$ of fracture fluid in the case of the samples from Kidd Creek Mine $2.9 \mathrm{~km}$. Concentrations of ${ }^{40} \mathrm{Ar}$ for the samples from $2.4 \mathrm{~km}(0.01)$, and in both Sudbury Mines (0.004 and $0.02 \mathrm{~cm}^{3}{ }^{40} \mathrm{Ar}$ per $\mathrm{cm}^{3}$ of fracture fluid respectively) are lower than this, but in all cases the radiogenic component accounts for an extraordinary over $93 \%$ of all ${ }^{40} \mathrm{Ar}$ present.

The 2013 samples reported for $2.4 \mathrm{~km}$ had ${ }^{40} \mathrm{Ar} /{ }^{36} \mathrm{Ar}$ ratios of up to $\sim 44,000$, which at the time were the highest crustal values ever measured in a free fluid. In this paper, ${ }^{40} \mathrm{Ar} /{ }^{36} \mathrm{Ar}$ ratios for samples from the deeper level of Kidd Creek Mine $(2.9 \mathrm{~km})$ reach in excess of 125,000 (102,000 average). The resampling of the fluids at $2.4 \mathrm{~km}$ depth revealed a lower ${ }^{40} \mathrm{Ar} /{ }^{36} \mathrm{Ar}$ ratio than in the 2013 study, with an average value of 15,100, compared with the previous average of 31,100. Radiogenic ages based on $\mathrm{He}, \mathrm{Ne}$ and Ar measurements are discussed in Section 4.10.

While the ${ }^{40} \mathrm{Ar} /{ }^{36} \mathrm{Ar}$ ratio for the two Sudbury mines are much lower than those in Kidd Creek Mine, an identifiable radiogenic excess from atmospheric ratio (295.5, Ozima and Podosek, 2002) is nonetheless observed. This ratio increases from 4353 in Mine 1 to 17589 in Mine 2. As noted with the ${ }^{40} \mathrm{Ar}$ excess, these high ${ }^{40} \mathrm{Ar} /{ }^{36} \mathrm{Ar}$ ratios all indicate fluids with a high radiogenic excess relative to the assumed starting composition. 


\subsection{Krypton}

All krypton abundances and ratios are given in Appendix A. As ${ }^{80} \mathrm{Kr}$ has no known production pathways within the crust (Ballentine and Burnard, 2002, and references therein) this is typically the isotope chosen for normalisation (in a method analogous to ${ }^{36} \mathrm{Ar}$ normalization discussed above). In this dataset, there are small deviations in ${ }^{78} \mathrm{Kr} /{ }^{80} \mathrm{Kr}$ and ${ }^{86} \mathrm{Kr} /{ }^{80} \mathrm{Kr}$ from atmosphere (Table A6), but no correlation with age or mass fractionation trends are observed.

\subsection{Xenon}

As per the standard approach in noble gas geochemistry, all Xe isotope data are normalised to ${ }^{130} \mathrm{Xe}$, the Xe isotope with no major radiogenic production pathways (Table 5). Compositions are expressed as in Figure 4 then as deviations relative to ${ }^{130} \mathrm{Xe}$, and elevated ${ }^{131-136} \mathrm{Xe} /{ }^{130} \mathrm{Xe}$ ratios are typical within the crust due to radioactive decay of uranium and plutonium. It is possible to determine the source of radiogenic xenon through comparison with the well-defined fission spectra for each parent radionuclide (Ballentine and Burnard, 2002 and references therein). By anchoring the ${ }^{238} \mathrm{U}$ fission spectra to ${ }^{136} \mathrm{Xe}$ a good agreement is observed between the predicted and observed ${ }^{131-134} \mathrm{Xe}$ excess in the samples (Figure 4). This indicates that the radiogenic xenon excess $\left(\mathrm{Xe}^{*}\right)$ in all locations can be explained via ${ }^{238} \mathrm{U}$ fission and accumulation of radiogenic $\mathrm{Xe}$ over time.

${ }^{136} \mathrm{Xe}^{*}$ is greatest in Kidd Creek Mine samples from $2.9 \mathrm{~km}\left(9.9 \times 10^{-10} \mathrm{~cm}^{3}{ }^{136} \mathrm{Xe}\right.$ per $\mathrm{cm}^{3}$ of fracture fluid) and is an order of magnitude greater than ${ }^{136} \mathrm{Xe}^{*}$ resampled from $2.4 \mathrm{~km}$ fluids 
$\left(7.1 \times 10^{-10} \mathrm{~cm}^{3}{ }^{136} \mathrm{Xe}\right.$ per $\mathrm{cm}^{3}$ of fracture fluid). In Sudbury samples, ${ }^{136} \mathrm{Xe}^{*}$ show a smaller range $\left(5.1 \times 10^{-11}\right.$ and $2.3 \times 10^{-10} \mathrm{~cm}^{3}{ }^{136} \mathrm{Xe}$ per $\mathrm{cm}^{3}$ of fracture fluid in Mines 1 and 2 respectively), consistent with a lower radiogenic excess in the fluids Mine 2 versus Mine 1 in the Sudbury Basin compared to Kidd Creek Mine fluids.

In addition to radiogenic xenon, a small excess over ASW is observed in the 'shielded' ( ${ }^{124-}$ ${ }^{128} \mathrm{Xe}$ ) isotopes which have no significant production within crustal environments (Ballentine and Burnard, 2002). These are given as percentages in Table 8.

By dividing the percentage deviation by the relative mass difference of the light isotope relative to ${ }^{130} \mathrm{Xe}$ the enrichment in shielded isotopes per amu is calculated. The average enrichment is observed to be the greatest in Kidd Creek Mine samples from $2.9 \mathrm{~km}$ (6.7 \%o) followed by Mine 2 (3.0 \%o), Kidd Creek Mine samples from 2.4 km (2.6 \%o) and lastly samples from Mine 1 (2.5 \%o). As was previously observed in Holland et al. (2013) the light Xe isotopes at both levels of Kidd Creek Mine also show an additional ${ }^{129}$ Xe excess far beyond that which may be linked by mass fractionation to the ${ }^{124-128}$ Xe excess (Table 8, Figure 5). A ${ }^{129}$ Xe excess was also observed in 2013 (Holland et al., 2013). The interpretation and implication of this is presented in Section 5.33 .

\subsection{Radiogenic noble gases}

At Kidd Creek Mine, resampling of previous boreholes from Holland et al. (2013) at $2.4 \mathrm{~km}$ depth indicate a reduction in all radiogenically-derived noble gas concentrations expressed as per 
$\mathrm{cm}^{3}$ of fracture fluid since initial sampling 44 months prior. In contrast, in the recently completed boreholes sampled immediately after drilling at $2.9 \mathrm{~km}$, the concentrations of noble gases within the fluids are the highest ever reported in the literature. The exception to this is xenon, which shows a similar radiogenic concentration to the samples collected in 2013 from $2.4 \mathrm{~km}$. In both Sudbury mines, a lower excess of radiogenic noble gases is observed per $\mathrm{cm}^{3}$ of fracture fluid (Table 4).

\subsection{Radiogenic residence time calculations}

The approach for deriving residence times for fracture fluids is as follows: 1. initial composition of the pore fluids is assumed to be approximately that of seawater at $10{ }^{\circ} \mathrm{C}$ with corresponding noble gas content; 2. gas phases are quantitatively recovered from the fluids during sampling; 3. reasonable estimates of combined matrix and fracture porosity (termed bulk porosity here) are applied; 4. noble gases behave conservatively; and 5. all radiogenic noble gases are produced in situ in a closed system within the crystalline rock formations.

In the case of the first assumption, given that the host rock was originally formed within a proximal marine environment (Thurston et al., 2008), it is reasonable to assume the initial pore fluids would be seawater with the corresponding noble gas content. Given the rate at which gas exsolved from the water phase (Table 1), coupled with the known strong affinity of noble gases for a gaseous phase (Crovetto et al., 1982; Ballentine et al., 2002; Warr et al., 2015), total degassing of the water phase can reasonably be ensured during sampling. In addition, degassing processes prior to sampling that affected noble gas concentrations for the samples from Kidd Creek Mine $2.9 \mathrm{~km}$ (Figure 2) can be corrected for as seen in Section 4.2. Bulk porosity estimates for crystalline rock of the Canadian Shield vary in a narrow range of $\sim 1 \%+/-0.45 \%$ 
with bulk porosity principally existing as fractures within the crystalline rock, decreasing as a function of depth as per Equation 3 (Sherwood Lollar et al., 2014 and references therein). Any gas phase not in solution is expected to occupy negligible volume within these fractures due to the hydrostatic-or-greater pressure of the system (Holland et al., 2013). In contrast, the assumption that all noble gases efficiently migrate into the fluid phase is a simplification at relatively low temperatures, even over up to $\mathrm{Ga}$ timescales, but within the closed system assumption means that the derived ages are minimum estimates. Release of the noble gases from the minerals in which they are produced will depend on the mineral size distribution, and both temporal and thermal history (Fulda and Lippolt, 2000; Lippmann et al., 2003; Baxter, 2010; Tolstikhin et al., 2014).

The final assumption is that of a closed system on a connected fracture fluid scale. For the systems presented here we use two lines of evidence to support this assumption. First, the ASWderived noble gases $\left({ }^{20} \mathrm{Ne},{ }^{84} \mathrm{Kr} \&{ }^{130} \mathrm{Xe}\right)$ show reasonable agreement with the assumed starting composition based on ${ }^{36} \mathrm{Ar}$ concentrations (Figure 2). Any noble gas loss/gain through diffusive or bulk gas phase migration in or out of the fracture network would likely result in major elemental fractionation, with neon being the most affected and xenon the least based on their respective diffusivities and differences in the relative partitioning between different phases. As discussed, this trend is not observed in any of the samples in this study (Figure 2). Additionally, any external exchange of noble gases would likely result in variable excesses in the radiogenic noble gases which would be reflected in poorly correlated radiogenic ages between the different noble gas systems $\left({ }^{4} \mathrm{He}^{*},{ }^{21} \mathrm{Ne}^{*},{ }^{40} \mathrm{Ar}^{*},{ }^{136} \mathrm{Xe}^{*}\right)$. Crucially this is not observed (Table 9). All residence time estimates are in agreement with one another within error (Table 9), with the exception of some variation outside uncertainty for the estimates derived from ${ }^{21} \mathrm{Ne}^{*}$ that is 
discussed in the following section. These two lines of evidence support that any exchange with external systems is negligible. Therefore, as in the 2013 study (Holland et al., 2013) all systems presented here are assumed to reflect closed systems on a regional/deposit scale.

\subsection{Radiogenic Ages}

Residence time estimates for fracture fluids are based on resolved radiogenic ${ }^{4} \mathrm{He}^{*},{ }^{21} \mathrm{Ne}^{*},{ }^{40} \mathrm{Ar}^{*}$ and ${ }^{136} \mathrm{Xe} *$ that accumulate in subsurface fluids due to radioactive decay of uranium, thorium and potassium over geologic timescales (Ballentine and Burnard, 2002). If these are assumed to have been produced in situ, an estimate of the time since isolation can be calculated.

The noble gas content per $\mathrm{cm}^{3}$ of host rock is calculated by multiplying the radiogenic noble gases concentrations per $\mathrm{cm}^{3}$ of fluid by an estimate of bulk porosity calculated using Equation 3 (Sherwood Lollar et al., 2014). This is converted into in situ radiogenic noble gas concentration per gram of host rock by dividing this number by typical density of crystalline rock $\left(\sim 2.7 \mathrm{~g} / \mathrm{cm}^{3}\right)$. Using this approach the noble gas content per gram of host rock is obtained. In order to derive residence times, the concentrations of the parent elements for each noble gas were taken from the literature. For Kidd Creek Mine the same Kidd Munro concentrations were used as from Holland et al., 2013 ( $\mathrm{Th}=9 \pm 0.2 \mathrm{ppm}, \mathrm{U}=2 \pm 0.1 \mathrm{ppm}$ and $\mathrm{K}=2 \% \pm 0.05$, based on values taken from Moulton et al., 2011) and for the Sudbury Mines the average tonalite gneiss from the Levack Gneiss Complex was used $(\mathrm{Th}=8 \pm 0.1 \mathrm{ppm}, \mathrm{U}=1 \pm 0.2 \mathrm{ppm}$ and $\mathrm{K}=1.86 \pm 0.05 \%$, Meldrum et al., 1997). These were combined with the respective decay constants and the total production per decay to estimate production as a function of time. The equations for ${ }^{4} \mathrm{He}^{*}$ and ${ }^{40} \mathrm{Ar}^{*}$ production are as follows: 
${ }^{4} \mathrm{He}^{*}=8 \times\left[{ }^{238} \mathrm{U}\right] \times\left(\mathrm{e}^{\lambda 238 \mathrm{t}}-1\right)+7 \times\left[{ }^{235} \mathrm{U}\right] \times\left(\mathrm{e}^{\lambda 235 \mathrm{t}}-1\right)+6 \times\left[{ }^{232} \mathrm{Th}\right] \times\left(\mathrm{e}^{\lambda 232 \mathrm{t}}-1\right)$

${ }^{40} \mathrm{Ar}^{*}=0.105 \times\left[{ }^{40} \mathrm{~K}\right] \times\left(\mathrm{e}^{\lambda 40 \mathrm{t}}-1\right)$

where $\left[{ }^{238} \mathrm{U}\right],\left[{ }^{235} \mathrm{U}\right],\left[{ }^{232} \mathrm{Th}\right]$ and $\left[{ }^{40} \mathrm{~K}\right]$ are elemental concentrations in ppm in the host rock, $\lambda_{238}$, $\lambda_{235}, \lambda_{232}$ and $\lambda_{40}$ are the decay constants $\left(\right.$ year $\left.^{-1}\right)$ 8, 7, 6 are the total atoms of ${ }^{4}$ He produced from the complete decay chain of each parent radionuclide, 0.105 is the ${ }^{40} \mathrm{~K}$ fraction which decays to ${ }^{40} \mathrm{Ar}$ and $t$ is time in years (Ballentine and Burnard, 2002; Holland et al., 2013).

As in the previous study (Holland et al., 2013), residence times for both ${ }^{21} \mathrm{Ne}^{*}$ and ${ }^{136} \mathrm{Xe}^{*}$ were derived using the relationship between ${ }^{4} \mathrm{He}^{*},{ }^{21} \mathrm{Ne}^{*}$ and ${ }^{136} \mathrm{Xe}^{*}\left(9.96 \times 10^{6}\right.$ and $3.033 \times 10^{8}$ for ${ }^{4} \mathrm{He}^{*} /{ }^{21} \mathrm{Ne}^{*}$ and ${ }^{4} \mathrm{He}^{*} /{ }^{136} \mathrm{Xe}^{*}$ respectively, Ballentine and Burnard, 2002). We assign error bars based on the maximum possible uncertainty associated with this calculation, which is the uncertainty in the bulk porosity estimate $(1 \%+/-0.45 \%$ adjusted for depth; Equation 3, after Sherwood Lollar et al., 2014 and references therein) combined in quadrature with the calculated analytical uncertainty and the published analytical uncertainty in the radioelement concentration. These ages and their corresponding $1 \sigma$ uncertainty are presented in Table 9 and Figure 6.

From Table 9 it is observed that all fracture fluids residence times agree with one another within uncertainty for boreholes within a given level at Kidd Creek Mine, with no discernible time series. This suggests that, as hypothesized in the conceptual model which we propose in Section 5.2 , boreholes from the same level of the mine are intersecting and draining fracture fluids with similar residence times. This is both supported by the similar noble gas isotopic compositions and fluid $\delta^{18} \mathrm{O}$ and $\delta^{2} \mathrm{H}$ data (Tables 2-8, 10). Accordingly, the method of averaging fluid data 
for all boreholes for a given mine level, as done in the 2013 study, remains valid for the data in the present study.

Based on the averages, the mean residence times of the fluids have decreased for the samples at $2.4 \mathrm{~km}$ depth at Kidd Creek Mine (0.2 to $0.6 \mathrm{Ga}, 0.4 \mathrm{Ga}$ average) since the initial 2013 study (1.1 to $1.7 \mathrm{Ga}, 1.2 \mathrm{Ga}$ average). This behaviour is consistent with the hydrogeological conceptual model of draining fracture fluids as which was discussed in more detail in Section 5.2.

At the deeper $(2.9 \mathrm{~km})$ level of Kidd Creek Mine, fluid mean residence times are the oldest yet reported (1.7 Ga average mean residence time). While ${ }^{21} \mathrm{Ne} *$ gives the youngest estimate (1.0 $\mathrm{Ga}){ }^{4} \mathrm{He}^{*},{ }^{40} \mathrm{Ar}^{*}$ and ${ }^{136} \mathrm{Xe}^{*}$ estimates are all consistent, with estimates ranging between 1.7 to $2.2 \mathrm{Ga}$. In the case of neon, the average age, calculated using the ${ }^{4} \mathrm{He}^{*} /{ }^{21} \mathrm{Ne}^{*}$ production rate in modern crust, is much lower than its radiogenic counterparts. This is discussed further in Section 5.5 .

While the fluids in both Sudbury mines have significantly younger mean residence times, they are still indicative of systems which have been hydrogeologically isolated over significant periods of time. With estimated mean residence times ranging from $0.2-0.6 \mathrm{Ga}$ (Mine 1) and $0.2-0.9 \mathrm{Ga}$ (Mine 2) these are still older than any previously published systems except for Kidd Creek Mine. Although Mine 1 helium and neon ages are greater than Mine 2, the opposite is observed for argon and krypton. This results in overall average residence times of 0.3 and $0.5 \mathrm{Ga}$ respectively. All ages are presented graphically in Figure 6.

\section{Discussion}


Despite their potential significance in global hydrogen production and deep carbon cycles the volume and distribution of these deep crustal fluids remain poorly constrained. Here the first global estimates of deep crustal reservoirs are calculated as a crucial first step to address this (Section 5.1). A newly-developed conceptual model is also presented in tandem which models distribution, volumes and residence times of fracture fluids within a vertical profile (Section 5.2). This model is expected to provide a much enhanced understanding of fracture fluids on a regional scale. This model is evaluated using both the data generated for this study and previously published data by Holland et al. (2013).

In the previously mentioned Holland et al. (2013) study three novel noble gas characteristics were observed: 1 . a ${ }^{129}$ Xe excess attributed to local sediments; 2. a ${ }^{124-128}$ Xe excess was identified and attributed to an early atmospheric component; and 3. an elevated ${ }^{21} \mathrm{Ne} /{ }^{22} \mathrm{Ne}$ end-member well above typical crustal values (Holland et al., 2013). In this study three new localities have been identified which clearly preserve fluids on similarly ancient timescales and allow evaluation of the original interpretation of these geochemical features and assess the common elements within other systems. Additionally, the original boreholes at $2.4 \mathrm{~km}$ depth at Kidd Mine have been resampled. The geochemical characteristics of each of these are used as the basis to validate key aspects of the proposed conceptual model.

5.1 Global estimates of deep crustal reservoirs

To assess the impact such deep old fracture fluids can have on global cycles it is also essential to have estimates of both their total volume and distribution within the crust. In a recent study Gleeson et al. (2016) used ${ }^{3} \mathrm{H}$ data to estimate the depth penetration of young $(<50-100$-year- 
old) groundwater in the first $2 \mathrm{~km}$ of the continental crust, and two-dimensional models of bulk porosity-depth relationships for different crustal rocks integrated with cross-sectional steadystate models of groundwater flow to estimate the global volume of modern groundwater. The analysis yielded the important insight that the volume of modern groundwater $\left(350,000 \mathrm{~km}^{3}\right.$ to $630,000 \mathrm{~km}^{3}$ for 50 year and 100-year-old water, respectively) is by far the largest component of the planet's active hydrologic cycle (with the exception of the oceans at $\sim 1$ billion $\mathrm{km}^{3}$ ). Given the central role of groundwater in sustaining the Earth's agricultural, social, economic activities, climate and ecosystems, this work generated widespread attention. The even more fundamental corollary of their findings, however, went unnoticed. Specifically, that the $\leq 630,000 \mathrm{~km}^{3}$ of groundwater that they estimated for modern groundwater $(<50-100$ years $)$ represents only 1.5 $2.8 \%$ of the total groundwater inventory to $2 \mathrm{~km}$ depth $\left(\sim 22.6\right.$ million $\mathrm{km}^{3}$; Gleeson et al., 2016). The result is that $97.2-98.5 \%$ of groundwater is much older, and we know almost nothing about the age or distribution of that immense "hidden hydrogeosphere" which is not actively interacting with the short-term hydrologic cycle. Similarly, the implications of this deep hydrogeosphere for the habitability of the Earth's crust and for subsurface ecosystems are also poorly constrained.

As Gleeson et al. (2016) noted, empirical databases for groundwater, even to $2 \mathrm{~km}$ depth, are rare - necessitating a modelling approach to derive even first order estimates of groundwater inventory. No estimate has yet been done on the volume of groundwater beyond this arbitrary 2 $\mathrm{km}$ cut-off, but a first order estimate can be made here. Below $2 \mathrm{~km}$ depth, the bulk of the terrestrial crust is crystalline basement (> $80 \%$ estimated in Gleeson et al. 2016). This estimate is consistent with surface area estimates for the Precambrian crust which indicate crystalline rocks of the Precambrian constitute $>30 \%$ of the exposed continental area at surface and $>72 \%$ 
of the bedrock surface area in total for the planet (Goodwin, 1996). Hence, for depths deeper than $2 \mathrm{~km}$ in the continental crust we can consider the Precambrian crust as a basis for a representative, but conservative, estimate for determining the groundwater inventory at depth. Including younger Paleozoic crystalline rocks would only increase this estimate and therefore can be neglected for this first order analysis.

Given the total surface area of the continents is $1.48 \times 10^{8} \mathrm{~km}^{2}$ and knowing that $72 \%$ of that crust is Precambrian crystalline rock $\left(1.06 \times 10^{8} \mathrm{~km}^{2}\right.$; Goodwin, 1996), we can calculate the volume of groundwater in the crust to depth by incorporating bulk porosity estimates. Measured values of bulk porosity within fractures for crystalline basement rocks range from 0.1 to $2.3 \%$ (Aquilina et al., 2004; Stober, 1997; Stober and Bucher, 2007) with a mean of $1 \% \pm 0.45 \%$ (2 $\sigma)$ (Bucher and Stober, 2010). Due to the limited number of such empirical measurements, Sherwood Lollar et al. (2014) took a modelling approach and estimate bulk porosity that exponentially declines with depth after the models of Bethke (1985). The equation is given as:

$\Phi=\left(1.6 \mathrm{e}^{-\mathrm{z} / 4.8}\right) / 100$

where $\phi$ is bulk porosity $(\%)$ and $z$ is depth $(\mathrm{km})$. To $10 \mathrm{~km}$ depth, this approach predicts an average bulk porosity of $0.96 \%$, consistent with the above measurements from the literature and the value used by Gleeson et al. (2016) for crystalline rocks of the upper crust.

The depth of water-filled fractures in the crust is more uncertain. At $>15 \mathrm{~km}$ depth, temperatures are likely too warm for brittle faulting and ductile creep persists (Sleep and Zoback, 2007). To at least $10 \mathrm{~km}$ however, brittle crust faults should contain water, likely under hydrostatic pressure (Townend and Zoback, 2000 and references therein). Using the surface area of Precambrian crystalline rock, an average bulk porosity of $1 \%$, to a depth of $10 \mathrm{~km}$ then, suggests another 8.5 
million $\mathrm{km}^{3}$ should be added to the groundwater inventory in addition to the 22.6 million $\mathrm{km}^{3}$ estimated for the top $2 \mathrm{~km}$ (Gleeson et al., 2016). This indicates that fluids residing in Precambrian crystalline basement may account for somewhere in the region of $30 \%$ of the total groundwater inventory of the earth. The residence times of this total groundwater inventory of >

30 million $\mathrm{km}^{3}$ is, to date, almost completely unknown. This study represents an important first step in addressing this gap through defining an approach for estimating the mean residence times of such fluids and expanding beyond the earlier study at Kidd Creek Mine to demonstrate that such ancient fluids (Ma to $\mathrm{Ga}$ ) are a characteristic feature of the Precambrian deep crust.

\subsection{Conceptual model}

Based on this study and previous investigations of saline fracture fluids in the deep Precambrian cratons (Sherwood Lollar et al., 2007; Lippman-Pipke et al., 2011; Holland et al., 2013), the following conceptual model has been developed to better constrain distribution, volumes and residence times of fracture fluids within a vertical profile (Figure 7). Fracture fluids in deep crystalline rock decrease in frequency and are increasingly hydrogeologically isolated one from another with increasing depth in the crust (Sleep and Zoback, 2007; Golders Associates 2010). Based on the results of Holland et al (2013), it is reasonable to assume that the deeper, more hydrogeologically isolated fractures contain fluids with the oldest residence times, and as a corollary, that less deep fractures will contain a larger volume of fluids with relatively less ancient residence time distributions.

Within the host rocks investigated in this study, the discrete fracture systems contain highly saline fluids and dissolved gases under pressure. The distribution of these fractures are the dominant control on bulk porosity and associated permeability. The fractures are highly variable 
in terms of geometry, spacing and structure which results in high variations in bulk porosity, permeability and fluid volume locally. While a few studies exist in Precambrian rock where the actual fracture distribution have been mapped (Manzi et al., 2012); such information is not typically available and does not exist for the sites investigated in this study. Conceptually however, it is clear that individual boreholes drilled into the crystalline rock intersect one or more these fracture networks, providing a means for the host fluids to migrate out of the host rock and any given borehole will intersect multiple fractures (Figure 7). Accordingly, the fluids sampled from each borehole are the sum total of all fluids being discharged from each contributing fracture. With each fracture containing fluids of possibly different geological residence times, the resulting noble gas-derived mean residence time for the samples collected at the borehole collar thus represents the mean residence time of all fluids contributing to the fracture flow. The borehole-specific mean residence times are dependent on the isolation age, the volumes and the fluid discharge rates for each contributing fracture. Where boreholes intersect the same fracture networks, this will result in similar geochemistry and residence times. This model for fractured rock is analogous to those applied to unconsolidated porous media in the sense that any groundwater is a composite reservoir contributed to from multiple flowlines with a certain degree of heterogeneity in provenance and age as a function of the hydrogeological setting (Bethke and Johnson, 2008; Goode, 1996). This "mixed reservoir" aspect of any hydrogeologic system is amplified for fractured rock systems due to the high degree of heterogeneity inherent to fractured rock (Golders Associates 2010). Over time, stress regimes within the host rock change, and in the tectonically quiescent rocks of the Precambrian Shields this is primarily caused by large scale, regional stress variations (Sleep and Zoback, 2007). Stress changes on a regional scale may result in both reactivation of pre-existing planes of weakness 
and the development of new, localised fractures. Localised changes to the stress regime may additionally be produced due to mining activity. Through all of these processes new, fluidbearing fractures are expected to contribute to the sampling boreholes over time. Since the preservation potential of these fracture networks is expected to be lower as a function of increasing age, statistically these fluids are likely to be representative of younger residence times.

As a result mean residence times may also change, as some fractures drain out and contribute less to the overall volume discharging form the boreholes while new ones become connected. Based on these considerations the new investigation at Kidd Creek Mine allows assessment of two hypotheses: a. that resampling of the Holland et al 2013 boreholes would show less ancient mean residence times as the contribution from the more older, isolated fractures decreased over time; and $\mathrm{b}$. the new deeper boreholes at $2.9 \mathrm{~km}$ would provide fluid mean residence times comparable to or even older than those of the Holland at al. 2013 study (Sleep and Zoback, 2007; Townend and Zoback, 2000). Where applicable we evaluate these hypotheses in the remainder of the discussion section using the geochemical data presented in this study.

One final point to consider within the conceptual model is the potential for natural bias within the sampled fluids which may too have a bearing on the calculated residence times. In this kind of environment fluids are principally considered to exist within fractures, rather than at grain boundaries or as fluid inclusions. The mean residence times of the fluids are therefore net combination of all fractures sampled. However, it is reasonable to consider that the larger fractures are more likely to be intersected by an exploratory borehole than their smaller-scale 
counterparts. Given that a relationship between fluid volume and residence time may exist (as hypothesised here) there may be a biasing towards boreholes sampling younger, rather than older fluids at any given level. Accordingly the mean residence times presented here would remain conservative estimates, even if there is a natural bias present in the fluids being sampled.

\section{$5.3^{129}$ Xe anomaly}

In the 2013 study a ${ }^{129} \mathrm{Xe}$ excess far in excess of any early atmosphere component or possible mantle component was identified in the fractures waters at Kidd Creek Mine. This was attributed to a radiogenic ${ }^{129} \mathrm{Xe}$ excess produced from ${ }^{129} \mathrm{I}$ likely sorbed to the carbon-rich formations of the Kidd Creek Mine deposit during deposition in a proximal seafloor environment. Preservation of the ${ }^{129} \mathrm{Xe}$ results from decay of ${ }^{129} \mathrm{I}$ was attributed to rapid periods of intense volcanism that quickly capped the sedimentary layers - creating a closed system in which ${ }^{129} \mathrm{I}$ (and resulting ${ }^{129} \mathrm{Xe}$ ) were sequestered (Holland et al., 2013). In this study an even greater ${ }^{129} \mathrm{Xe} /{ }^{130} \mathrm{Xe}$ excess is identified in the fluids from $2.9 \mathrm{~km}$ at Kidd Creek Mine. The increase in ${ }^{129} \mathrm{Xe} /{ }^{130} \mathrm{Xe}$ ratios however is small compared to the ${ }^{136} \mathrm{Xe} /{ }^{130} \mathrm{Xe}$ ratio. In contrast, a very large ${ }^{136} \mathrm{Xe} /{ }^{130} \mathrm{Xe}$ deviation is observed from $21 \%$ to $87 \%$ (i.e. $4.1 \pm 0.5$ times higher in the $2.9 \mathrm{~km}$ samples versus those from $2.4 \mathrm{~km})$. The ${ }^{129} \mathrm{Xe} /{ }^{130} \mathrm{Xe}$ only increases from $1.2 \%$ to $3.8 \%(3.3 \pm 0.6$ times higher. Though these values lie within uncertainty of one another, based on standard deviation, when standard error is calculated (which can be used in this case to evaluate the accuracy of the mean value) these values lie outside of uncertainty of one another $(4.1 \pm 0.2 \& 3.3 \pm 0.3)$ indicating the average increases are distinct for these two isotopes. 
This lack of proportional co-variation between the radiogenic ${ }^{136} \mathrm{Xe}$, and sedimentary-derived ${ }^{129} \mathrm{Xe}$, is not consistent with a single homogenised ancient fluid of uniform age (containing the ${ }^{129}$ Xe excess) mixing variably with a single modern fluid component to produce the obseryed excesses. Instead, this supports the interpretation that boreholes at $2.4 \mathrm{~km}$ and $2.9 \mathrm{~km}$ sample different fracture systems, consistent with the proposed conceptual model of hydrogeologically isolated fracture networks preserving fluids of different provenance and age. As a result, different ${ }^{129} \mathrm{Xe}$ and ${ }^{136} \mathrm{Xe}$ excesses in the fluids could result from variances in the ${ }^{129} \mathrm{Xe}$ excess (due to different degrees of water-rock interaction), coupled with an isolation age-dependent ${ }^{136} \mathrm{Xe} *$ component.

In contrast to the Kidd Creek Mine fluids, no ${ }^{129}$ Xe excess is observed in either of the two Sudbury mines. Given that the Sudbury Basin system was the loci of a major bolide impact at 1.8 $\mathrm{Ga}$, massively fracturing the terrain on a regional scale over hundreds of $\mathrm{km}$, the absence of the ${ }^{129} \mathrm{Xe}$ excess observed at the well-preserved Kidd Creek Mine deposit was expected. This highlights the ability of noble gases to discern between the distribution of fracture fluids of different age and provenance as a function of different geologic settings.

\subsection{Ancient atmospheric signal}

A fractionated excess in the shielded xenon isotopes $\left({ }^{124-128} \mathrm{Xe}\right)$ relative to modern air values is present in ancient fracture fluids and may also be present in the ${ }^{131-136} \mathrm{Xe}$ isotopes (Appendix C). These cannot be explained using any known xenon production pathways or in situ mass fractionation processes (which would affect all xenon isotopes) and have previously been 
attributed to atmospheric Xe loss over geological time by ionisation of xenon in the early atmosphere (Pujol et al., 2009; Pujol et al., 2011, Avice 2014). This has been used as basis for resolving the 'xenon paradox'; the observation that Earth has $~ 90 \%$ lower Xe abundance than predicted by meteorite and Solar abundance patterns (Anders and Owen, 1977; Podosek and Ozima, 2000; Pepin and Porcelli, 2002). The atmosphere Xe loss model has been used to derive an atmospheric isotopic evolution curve for xenon, from an initial Xe-U/solar composition evolving to modern values (Pujol et al., 2011; Holland et al., 2013; Avice and Marty, 2014). The exact mechanisms and rates involved in this isotopic fractionation and loss are presently poorly constrained (Avice and Marty, 2014; Hébrard and Marty, 2014). Current models are exclusively based on xenon data from fluid inclusions (e.g. Pujol et al., 2011; Avice and Marty, 2014), the majority of which are greater than $2 \mathrm{Ga}$ (Hébrard and Marty, 2014). To date, data covering the 2 $\mathrm{Ga}$ - present day timescale is sparse. Expanding the dataset to cover this range will allow for better constraints on the rates and timing of the xenon isotopic evolution of the Earth's atmosphere over planetary timescales; and identification of the mechanism that may control any such process (Hébrard and Marty, 2014). To investigate this aspect of atmospheric Xe in the light of the samples in this study, Figure 5 (and Table 8) show the data for all the light excesses of Xe relative to modern atmosphere.

An average ${ }^{124-128} \mathrm{Xe}$ excess is observed for all samples (Figure 5). Once again samples from 2.9 $\mathrm{km}$ depth show the largest excesses, while the resampled fracture fluids at $2.4 \mathrm{~km}$ show a smaller excess compared to the initial 2013 observation. This trend is in agreement with a hydrogeologic conceptual model which predicts that due to fractures draining over time a younger mean residence time will be observed in these boreholes, as well as either a lower (or even no) ${ }^{124-}$ ${ }^{128} \mathrm{Xe}$ excess. This model is summarised in Section 5.2. This is because exact ${ }^{124-128} \mathrm{Xe}$ excess 
present within a fracture fluid is dependent on three key factors; 1. the rates, evolution and termination of the process driving this fractionation, 2. The point at which the fracture fluid became isolated from the early atmosphere and, 3 the relative proportion of each fracture fluid component within the fracture network.

The presence of a resolvable ${ }^{124-128} \mathrm{Xe}$ excess in the Sudbury system fluids is of particular interest. These are the fluids with the youngest mean residence times $(0.3-0.5 \mathrm{Ga})$ in which such a signal has been identified and indicates that at both locations one or more of the oldest fracture fluid components (which combined yield the mean residence times) contain an early atmospheric Xe signal. In addition we argue that the concept of such shallow $(<2 \mathrm{~km})$ fractures preserving fluids from before the SIC-forming impact event is unrealistic. This is due to the magnitude and scope of the event which is the second largest impact identified globally and caused ejecta to spread over at least a $650 \mathrm{~km}$ radius (Grieve and Therriault, 2000; Jirsa et al., 2011). Any fluid components in either Sudbury mine are therefore likely younger than the impact event at 1.85 $\mathrm{Ga}$. The implication of this is that the fractionation mechanisms proposed to create the ${ }^{124-128} \mathrm{Xe}$ anomalies noted in previous literature must in fact have continued beyond $2 \mathrm{Ga}$ and has been preserved in one or more fluid components. These fluid components, likely combined with younger fluids, have subsequently resulted in the calculated mean residence times $0.3 \& 0.5 \mathrm{Ga}$ for the two Sudbury mines. The identification of an early atmospheric Xe component in fluids younger than $1.85 \mathrm{Ga}$ is more consistent with models which indicate ionisation of the atmospheric Xe continuing until more recently (Pujol et al., 2011; Hébrard and Marty, 2014) rather than those which suggest it ended earlier than 2 Ga (Avice and Marty, 2014). Further investigation of this novel type of sample containing early atmospheric Xe components in 
addition to the traditional reliance on fluid inclusions, will allow better evaluation of alternative Xe loss mechanisms such as hydro-dynamic escape (Pepin, 2000).

\subsection{Ancient neon signal}

Nucleogenic neon in Precambrian systems have recently been shown to have a distinct ${ }^{21} \mathrm{Ne} /{ }^{22} \mathrm{Ne}$ end-member $\left({ }^{21} \mathrm{Ne} /{ }^{22} \mathrm{Ne}=3.1-3.5\right.$ at the ${ }^{20} \mathrm{Ne} /{ }^{22} \mathrm{Ne}$ intercept $)$ compared to the canonical values previously observed for the crust (Kendrick et al., 2011; Lippmann-Pipke et al., 2011; Holland et al, 2013). Typically nucleogenic ${ }^{21} \mathrm{Ne} /{ }^{22} \mathrm{Ne}$ end-members have values of $0.47-0.79$ at the ${ }^{20} \mathrm{Ne} /{ }^{22} \mathrm{Ne}$ intercept for modern crustal production (Kennedy et al., 1990; Ballentine and Burnard, 2002). Given that nucleogenic neon is produced via ${ }^{17,18} \mathrm{O}(\alpha, \mathrm{n}){ }^{20,21} \mathrm{Ne},{ }^{19} \mathrm{~F}(\alpha, \mathrm{n}){ }^{22} \mathrm{Na}\left(\beta^{+}\right){ }^{22} \mathrm{Ne}$ and ${ }^{19} \mathrm{~F}(\alpha, \mathrm{p}){ }^{22} \mathrm{Ne}$ (Wetherill, 1954), the dominant control on ${ }^{21} \mathrm{Ne} /{ }^{22} \mathrm{Ne}$ production is the ratio of oxygen to fluorine $(\mathrm{O} / \mathrm{F})$ in the proximity of $\mathrm{U}$ and Th-derived $\alpha$ particles $(\sim 40 \mu \mathrm{m}$ Wetherill, 1954; Kennedy et al, 1990; Ballentine 1997; Ballentine and Burnard, 2002). In modern crust, ${ }^{21} \mathrm{Ne} /{ }^{22} \mathrm{Ne}$ production rates are lower by a factor of $\sim 8$ based on that predicted by average $\mathrm{O} / \mathrm{F}$ ratios (Kennedy et a1, 1990; Ballentine 1997; Ballentine and Burnard, 2002; Lippmann-Pipke et al., 2011). This has been interpreted as a relative localised enrichment of $\mathrm{F}$ within Th and Ubearing minerals resulting in a greater ${ }^{22} \mathrm{Ne}$ production than expected based on the bulk ratios (Kennedy et al., 1990). In Precambrian rocks, however, depletion in F has been observed resulting in bulk $\mathrm{O} / \mathrm{F}$ ratios being elevated by roughly an order of magnitude (Lippmann-Pipke et al., 2011). This relative F deficit, resulting in reduced ${ }^{22} \mathrm{Ne}$ production, has been suggested as the potential cause for the elevated ${ }^{21} \mathrm{Ne} /{ }^{22} \mathrm{Ne}{ }^{21} \mathrm{Ne} /{ }^{22} \mathrm{Ne}$ end-member values $>3$ observed for the first time in the fracture waters of the South African gold mines (Lippmann-Pipke et al., 2011). 
In this study, with the exception of Mine 2, all fluid samples also show elevated ${ }^{21} \mathrm{Ne} /{ }^{22} \mathrm{Ne}$ relative to ${ }^{20} \mathrm{Ne} /{ }^{22} \mathrm{Ne}$ (Figure 3). Lippmann-Pipke et al. (2011) attributed this to release of $\mathrm{Ne}$ rich fluid inclusions from an earlier Precambrian source into the sampled younger fracture fluids (Lippmann-Pipke et al., 2011). However, in the case of Kidd Creek Mine, a similar explanation (fluid inclusion leakage) would require significant volumes of fluid addition from inclusion given the large volumes of water produced from these fracture fluid networks (Holland et al., 2013; Table 1). The simplest explanation is that the nucleogenic ${ }^{21} \mathrm{Ne} /{ }^{22} \mathrm{Ne}$ is a component of the original fracture fluids and has been produced based on the average $\mathrm{O} / \mathrm{F}$ ratios within $\sim 40 \mu \mathrm{m}$ of any $\alpha$ emitters $(\mathrm{U} \& \mathrm{Th}$ ) within the host rock. This average $\mathrm{O} / \mathrm{F}$ ratio within would need to be greater than that of the modern crust by a factor of 4.9. This is lower than that observed by Lippmann-Pipke et al. (11.9) in rocks aged between $2.7-3.1 \mathrm{Ga}$. Although a speculative relationship between age and evolving ${ }^{21} \mathrm{Ne} /{ }^{22} \mathrm{Ne}$ crustal production ratios might be inferred, this difference may also simply reflect the specific formation histories and mineralogy of each locality and warrants further investigation.

\subsection{Temporal evolution in the context of a hydrogeologic conceptual model for fracture networks}

This study provides the longest temporal record of deep fracture fluids published to date. The resampling of $2.4 \mathrm{~km}$ depth after 44 months provides insight into the temporal evolution of this system. All radiogenic excesses per $\mathrm{cm}^{3}$ of fluid decreased and radiogenic/non-radiogenic ratios evolved towards ASW ratios. In the case of ${ }^{4} \mathrm{He}$, average abundances per $\mathrm{cm}^{3}$ of fluid decreased by a factor of 1.85 . At the same time the ${ }^{40} \mathrm{Ar} /{ }^{36} \mathrm{Ar}$ ratio and the ${ }^{136} \mathrm{Xe} /{ }^{130} \mathrm{Xe} \%$ deviation 
decreased by factors of 2.07 and 1.86 respectively. In the case of neon a vector-based approach is applied. For this, the shift of each average ${ }^{20} \mathrm{Ne} /{ }^{22} \mathrm{Ne} \&{ }^{21} \mathrm{Ne} /{ }^{22} \mathrm{Ne}$ from the starting (ASW) composition was calculated and combined using the formula $a^{2}+b^{2}=c^{2}$. By dividing the combined value from the original study by the resampled combined value from the data presented here the relative decrease in radiogenic isotopes is quantified. This reveals a radiogenic reduction by a factor of 1.95 which is in line with that of the other isotope systems.

This consistent reduction of all noble gas excesses indicates a bulk (i.e. unfractionated) change in the mixing ratio between the initial ancient end-member composition as documented in Holland et al. (2013) and a less ancient component resulting in reduction in mean residence times. $\delta^{2} \mathrm{H}$ and $\delta^{18} \mathrm{O}$ values continue to rule out any modern meteoric fluid component impacting these samples (Table 10, Figure 8). Hence this secondary fluid must represent younger, but still old fluids discharging from the fracture network and contributing to the overall fluid discharging at the borehole collar (point of sampling). Such fluid evolution is consistent with the proposed conceptual model (Section 5.2).

\section{Summary/conclusions}

This work highlights that the isolated ancient fluid system discovered at $2.4 \mathrm{~km}$ depth in 2013 is not unique. We have expanded from this initial discovery to include three additional isolated fluid systems with average mean residence times spanning from 0.3 to $1.7 \mathrm{Ga}$. 
The deeper level at Kidd Mine reveal the oldest mean fluid residence times ever encountered in free fluids $(1.7 \mathrm{Ga})$. The resampled $2.4 \mathrm{~km}$ meanwhile indicates the addition of younger, yet still old fracture fluids, consistent with the conceptual model for these types of system. As the distance between the two levels is sufficient for the fluids to be isotopically distinct from one another, isolation between the two levels can be inferred. This gives additional constraints over the maximum size of the fluid reservoirs contributing to each system. The isolation occurred earlier for the deeper level based on radiogenic and early atmospheric ages which also fits with the proposed conceptual model. Outside of Kidd Mine the two new mines in the Sudbury system both indicate younger mean fluid residence times $(0.3 \mathrm{Ga}$ and $0.5 \mathrm{Ga}$ for Mine 1 \& 2 respectively) revealing the presence of 'meso-age' systems as well as the truly ancient. In all localities, a shielded xenon anomaly is present which has typically been attributed to an early atmosphere component. Given the timing of the Sudbury impact, which puts a maximum age on the oldest fluid component within these two mine systems $(1.849 \mathrm{Ga})$, this work therefore reveals the process which fractionated xenon was still in operation beyond $2 \mathrm{Ga}$.

The discovery of each additional system suggests that ancient fluids may be far more pervasive within the deep crust than originally thought. Consequently, their occurrence needs to be more extensively documented, and quantitatively estimated. Future noble gas studies can identify additional ancient fluid systems, assess the volumes involved and determine the degree of hydrogeologic connection or isolation, from surface systems. Crucially though, the noble gases provide a temporal timeframe which can be combined with additional noble gas, stable isotope and biological investigation to glean insight into the geochemical and biological evolution of our planet. 


\section{Acknowledgements}

This study was supported by the Canada Research Chairs program, Natural Sciences and Engineering Research Council of Canada Discovery and Accelerator grants, and additional funding from the Deep Carbon Observatory and Nuclear Waste Management Agency. Thanks are due to colleagues and supporters at the mines whose efforts and support for the sampling program were invaluable.

\section{References}

Anders E. and Owen T. (1977) Mars and Earth: Origin and Abundance of Volatiles. Science 198, 453-465.

Aquilina, L., de Dreuzy, J.-R., Bour, O. and Davy, P. (2004) Porosity and fluid velocities in the upper continental crust ( 2 to $4 \mathrm{~km}$ ) inferred from injection tests at the Soultz-sous-Forêts geothermal site. Geochimica et Cosmochimica Acta 68, 2405-2415.

Avice, G. and Marty, B. (2014) The iodine-plutonium-xenon age of the Moon-Earth system revisited. Philosophical Transactions of the Royal Society a-Mathematical Physical and Engineering Sciences 372.

Ballentine, C.J., Burgess, R. and Marty, B. (2002) Tracing fluid origin, transport and interaction in the crust in Porcelli, D., Ballentine, C. J., \& Wieler, R. (Eds.), Noble Gases in Geochemistry and Cosmochemistry. Reviews in Mineralogy and Geochemistry. Mineralogical Society of America, pp. 539-614.

Ballentine, C.J. and Burnard, P.G. (2002) Production, release and transport of noble gases in the continental crust in Porcelli, D., Ballentine, C. J., \& Wieler, R. (Eds.), Noble Gases in Geochemistry and Cosmochemistry. Reviews in Mineralogy and Geochemistry. Mineralogical Society of America, pp. 481-538.

Ballentine, C.J. and Hall, C.M. (1999) Determining paleotemperature and other variables by using an error-weighted, nonlinear inversion of noble gas concentrations in water. Geochimica et Cosmochimica Acta 63, 2315-2336.

Ballentine C. J. (1997) Resolving the mantle He/Ne and crustal $21 \mathrm{Ne} / 22 \mathrm{Ne}$ in well gases. Earth and Planetary Science Letters 152, 233-249.

Ballentine C. J., Onions R. K., Oxburgh E. R., Horvath F. and Deak J. (1991) Rare gas constraints on hydrocarbon accumulation, crustal degassing and groundwater flow in the Pannonian Basin. Earth and Planetary Science Letters 105, 229-246.

Barry P. H., Lawson M., Meurer W. P., Warr O., Mabry J. C., Byrne D. J. and Ballentine C. J. 
(2016) Noble gases solubility models of hydrocarbon charge mechanism in the Sleipner Vest gas field. Geochimica Et Cosmochimica Acta 194, 291-309.

Baxter, E.F. (2010) Diffusion of Noble Gases in Minerals. Reviews in Mineralogy and Geochemistry 72, 509-557.

Berger, B.R., Bleeker, W., van Breemen, O., Chapman, J.B., Peter, J.M., Layton-Matthews, D. and Gemmell, J.B. (2011) Results from the Targeted Geoscience Initiative III Kidd-Munro Project. Open File Report 6258.

Bethke, C.M. (1985) A numerical model of compaction-driven groundwater flow and heat transfer and its application to the paleohydrology of intracratonic sedimentary basins. Journal of Geophysical Research: Solid Earth 90, 6817-6828.

Bethke, C.M. and Johnson, T.M. (2008) Groundwater age and groundwater age dating. Annual Review of Earth and Planetary Sciences 36, 121-152.

Bleeker, W. and Parrish, R.R. (1996) Stratigraphy and U-Pb zircon geochronology of Kidd Creek: Implications for the formation of giant volcanogenic massive sulphide deposits and the tectonic history of the Abitibi greenstone belt. Canadian Journal of Earth Sciences 33, 12131231.

Bucher, K. and Stober, I. (2010) Fluids in the upper continental crust. Geofluids 10, 241-253.

Card K. D. (1994) Geology of the Levack gneiss complex, the northern footwall of the Sudbury structure, Ontario., Geological Survey of Canada.

Chivian, D., Brodie, E.L., Alm, E.J., Culley, D.E., Dehal, P.S., DeSantis, T.Z., Gihring, T.M., Lapidus, A., Lin, L.H., Lowry, S.R., Moser, D.P., Richardson, P.M., Southam, G., Wanger, G., Pratt, L.M., Andersen, G.L., Hazen, T.C., Brockman, F.J., Arkin, A.P. and Onstott, T.C. (2008) Environmental genomics reveals a single-species ecosystem deep within earth. Science 322, 275278.

Crovetto, R., Fernandez-Prini, R. and Japas, M.L. (1982) Solubilities of inert gases and methane in $\mathrm{H}_{2} \mathrm{O}$ and in $\mathrm{D}_{2} \mathrm{O}$ in the temperature range of 300 to $600 \mathrm{~K}$. Journal of Chemical Physics 76, 1077-1088.

Davis, D.W. (2008) Sub-million-year age resolution of Precambrian igneous events by thermal extraction-thermal ionization mass spectrometer $\mathrm{Pb}$ dating of zircon: Application to crystallization of the Sudbury impact melt sheet. Geology 36, 383-386.

Davis D. W., Schandl E. S. and Wasteneys H. A. (1994) U-Pb dating of minerals in alteration halos of Superior Province massive sulfide deposits: syngenesis versus metamorphism. Contributions to Mineralogy and. Petrology 115, 427-437.

Etiope G. and Sherwood Lollar B. (2013) Abiotic methane on earth. Reviews of Geophyics 51, 276-299.

Frape S. K., Fritz P. and Mcnutt R. H. (1984) Water Rock Interaction and Chemistry of Groundwaters from the Canadian Shield. Geochimica et Cosmochimica Acta 48, 1617-1627. 
Fulda, C. and Lippolt, H.J. (2000) Diffusion coefficients of noble gases in natural minerals: An apparent experimental time dependence caused by domain size spectra. Mathematical Geology $32,31-47$.

Gleeson, T., Befus, K.M., Jasechko, S., Luijendijk, E. and Cardenas, M.B. (2016) The global volume and distribution of modern groundwater. Nature Geoscience 9, 161-167.

Goode, D.J. (1996) Direct simulation of groundwater age. Water Resources Research 32, 289296.

Goodwin, A.M. (1996) Chapter 1 - Distribution and Tectonic Setting of Precambrian Crust, Principles of Precambrian Geology. Academic Press, London, pp. 1-50.

Graham, D.W. (2002) Noble gas isotope geochemistry of Mid-Ocean Ridge and Ocean Island Basalts: Characterization of mantle source reservoirs in Porcelli, D., Ballentine, C. J., \& Wieler, R. (Eds.), Noble Gases in Geochemistry and Cosmochemistry. Reviews in Mineralogy and Geochemistry. Mineralogical Society of America.

Grieve R. and Therriault A. (2000) Vredefort, Sudbury, Chicxulub: three of a kind? Annual Review of Earth and Planetary Sciences 28, 305-338.

Hébrard, E. and Marty, B. (2014) Coupled noble gas-hydrocarbon evolution of the early Earth atmosphere upon solar UV irradiation. Earth and Planetary Science Letters 385, 40-48.

Holland, G., Sherwood Lollar, B., Li, L., Lacrampe-Couloume, G., Slater, G.F. and Ballentine, C.J. (2013) Deep fracture fluids isolated in the crust since the Precambrian era. Nature 497, 357.

James R. S. and Golightly J. P. (2009) Metamorphism and Metasomatism. In A Field Guide to the Geology of Sudbury (eds. D. Rousell and G. H. Brown).

Jirsa M. A., Fralick P. W., Weiblen P. W. and Anderson J. L. B. (2011) Sudbury impact layer in the western Lake Superior region. Field Guide. 24, 147-169.

Kendrick M. A., Honda M., Walshe J. and Petersen K. (2011) Fluid sources and the role of abiogenic-CH4 in Archean gold mineralization: Constraints from noble gases and halogens. Precambrian Research 189, 313-327.

Kennedy, B.M., Hiyagon, H. and Reynolds, J.H. (1990) Crustal neon: A striking uniformity. Earth and Planetary Science Letters 98, 277-286.

Kietäväinen, R. and Purkamo, L. (2015) The origin, source, and cycling of methane in deep crystalline rock biosphere. Frontiers in Microbiology 6, 725.

Kipfer, R., Aeschbach-Hertig, W., Peeters, F. and Stute, M. (2002) Noble gases in lakes and ground waters in Porcelli, D., Ballentine, C. J., \& Wieler, R. (Eds.), Noble Gases in

Geochemistry and Cosmochemistry. Reviews in Mineralogy and Geochemistry. Mineralogical Society of America, pp. 615-700.

Krogh T. E., Davis D. W. and Corfu F. (1984) Precise U-Pb zircon and baddeleyite ages for the Sudbury area. In The geology and ore deposits of the Sudbury structure Ontario: Ontario Geological Survey. pp. 431-446.

Lau M. C. Y., Kieft T. L., Kuloyo O., Linage-Alvarez B., van Heerden E., Lindsay M. R., Magnabosco C., Wang W., Wiggins J. B., Guo L., Perlman D. H., Kyin S., Shwe H. H., Harris R. L., Oh Y., Yi M. J., Purtschert R., Slater G. F., Ono S., Wei S., Li L., Sherwood Lollar B. and 
Onstott T. C. (2016) An oligotrophic deep-subsurface community dependent on syntrophy is dominated by sulfur-driven autotrophic denitrifiers. Procedings of the Natural Academy of Science 113, E7927-E7936.

Li L., Wing B. A., Bui T. H., McDermott J. M., Slater G. F., Wei S., Lacrampe-Couloume G. and Sherwood Lollar B. (2016) Sulfur mass-independent fractionation in subsurface fracture waters indicates a long-standing sulfur cycle in Precambrian rocks. Nature Communications 7.

Lin, L.H., Wang, P.L., Rumble, D., Lippmann-Pipke, J., Boice, E., Pratt, L.M., Sherwood Lollar, B., Brodie, E.L., Hazen, T.C., Andersen, G.L., DeSantis, T.Z., Moser, D.P., Kershaw, D. and Onstott, T.C. (2006) Long-term sustainability of a high-energy, low-diversity crustal biome. Science 314, 479-482.

Lippmann-Pipke, J., Sherwood Lollar, B., Niedermann, S., Stroncik, N.A., Naumann, R., van Heerden, E. and Onstott, T.C. (2011) Neon identifies two billion year old fluid component in Kaapvaal Craton. Chemical Geology 283, 287-296.

Lippmann, J., Stute, M., Torgersen, T., Moser, D.P., Hall, J.A., Lin, L., Borcsik, M., Bellamy, R.E.S. and Onstott, T.C. (2003) Dating ultra-deep mine waters with noble gases and ${ }^{36} \mathrm{Cl}$, Witwatersrand Basin, South Africa. Geochimica Et Cosmochimica Acta 67, 4597-4619.

Long, D.G.F. (2009) The Huronian Supergroup, in: Rousell, D., Brown, G.H. (Eds.), A Field Guide to the Geology of Sudbury. Ontario Geological Survey.

Magnabosco, C., Ryan, K., Lau, M.C.Y., Kuloyo, O., Sherwood Lollar, B., Kieft, T.L., van Heerden, E. and Onstott, T.C. (2016) A metagenomic window into carbon metabolism at $3 \mathrm{~km}$ depth in Precambrian continental crust. ISME Journal 10, 730-741.

Mamyrin B. A., Anufriyev G. S., Kamensky I. L. and Tolstikhin I. N. (1970) Determination of the isotopic composition of atmospheric helium. Geochemistry International, 498-505.

Manzi M., Durrheim R. J., Hein K. A. A. and King N. (2012) 3D edge detection seismic attributes used to map potential conduits for water and methane in deep gold mines in the Witwatersrand basin, South Africa. Geophysics 77, 133-147.

Meldrum, A., AbdelRahman, A.F.M., Martin, R.F. and Wodicka, N. (1997) The nature, age and petrogenesis of the Cartier batholith, northern flank of the Sudbury structure, Ontario, Canada. Precambrian Research 82, 265-285.

Moulton B. J. A., Fowler A. D., Ayer J. A., Berger B. R. and Mercier-Langevin P. (2011) Archean subqueous high-silica rhyolite coulées: Examples from the Kidd-Munro Assemblage in the Abitibi Subprovince. Precambrian Research 189, 389-403.

Onstott T. C., Hinton S. M., Silver B. J. and King H. E. (2010) Coupling hydrocarbon degradation to anaerobic respiration and mineral diagenesis: Theoretical constraints. Geobiology 8, 69-88.

Ozima, M. and Podosek, F.A. (2002) Noble Gas Geochemistry, Second Edition ed. Cambridge University Press.

Pattison E. F. (2009) Sudbury Igneous Complex. In A Field Guide to the Geology of Sudbury (eds. D. Rousell and G. H. Brown).

Pedersen M., Iversen S., Sorensen K. and Johansen E. (2005) The long and winding road from 
the research laboratory to industrial applications of lactic acid bacteria. FEMS Microbiol. Rev. $29,611-624$.

Pepin R. O. and Porcelli D. (2002) Origin of noble gases in the terrestrial planets in Porcelli, D., Ballentine, C. J., \& Wieler, R. (Eds.). In Noble Gases in Geochemistry and Cosmochemistry. Reviews in Mineralogy and Geochemistry Mineralogical Society of America. pp. 191-246.

Pepin, R.O. (2000) On the Isotopic Composition of Primordial Xenon in Terrestrial Planet Atmospheres. Space Science Reviews 92, 371-395.

Podosek F. A. and Ozima M. (2000) The xenon age of the Earth. Origin of the Earth and Moon 1, 63-72.

Pujol, M., Marty, B. and Burgess, R. (2011) Chondritic-like xenon trapped in Archean rocks: A possible signature of the ancient atmosphere. Earth and Planetary Science Letters 308, 298-306.

Pujol, M., Marty, B., Burnard, P. and Philippot, P. (2009) Xenon in Archean barite: Weak decay of 130Ba, mass-dependent isotopic fractionation and implication for barite formation.

Geochimica et Cosmochimica Acta 73, 6834-6846.

Sherwood Lollar, B., Onstott, T.C., Lacrampe-Couloume, G. and Ballentine, C.J. (2014) The contribution of the Precambrian continental lithosphere to global $\mathrm{H}_{2}$ production. Nature 516, 379-382.

Sherwood Lollar, B. and Ballentine, C.J. (2009) Insights into deep carbon derived from noble gases. Nature Geoscience 2, 543-547.

Sherwood Lollar B., Voglesonger K., Lin L.-H., Lacrampe-Couloume G., Telling J., Abrajano T. A., Onstott T. C. and Pratt L. M. (2007) Hydrogeologic controls on episodic H2 release from Precambrian fractured rocks - energy for deep subsurface life on Earth and Mars. Astrobiology 7, 971-986.

Sherwood Lollar, B., Lacrampe-Couloume, G., Slater, G.F., Ward, J., Moser, D.P., Gihring, T.M., Lin, L.H. and Onstott, T.C. (2006) Unravelling abiogenic and biogenic sources of methane in the Earth's deep subsurface. Chemical Geology 226, 328-339.

Sherwood Lollar B., Westgate T. D., Ward J. A., Slater G. F. and Lacrampe-Couloume G. (2002) Abiogenic formation of alkanes in the Earth's crust as a minor source for global hydrocarbon reservoirs. Nature 416, 522-524.

Sherwood Lollar B., Frape S. K., Weise S. M., Fritz P., Macko S. A. and Welhan J. A. (1993) Abiogenic methanogenesis in crystalline rocks. Geochimica Et Cosmochimica Acta 57, 50875097.

Sleep, N.H. and Zoback, M.D. (2007) Did earthquakes keep the early crust habitable? Astrobiology 7, 1023-1032.

Smith, S.P. (1985) Noble gas solubility in water at high temperature. Transactions - American Geophysical Union 66, 397-397.

Smith, S.P. and Kennedy, B.M. (1983) The solubility of noble gases in water and in $\mathrm{NaCl}$ brine. Geochimica Et Cosmochimica Acta 47, 503-515. 
Stober, I. and Bucher, K. (2007) Hydraulic properties of the crystalline basement. Hydrogeology Journal 15, 213-224.

Stober, I. (1997) Permeabilities and Chemical Properties of Water in Crystalline Rocks of the Black Forest, Germany. Aquatic Geochemistry 3, 43-60.

Stout, V.L. and Gibbons, M.D. (1955) Gettering of Gas by Titanium. Journal of Applied Physics 26, 1488-1492.

Thurston, P., Ayer, J., Goutier, J. and Hamilton, M. (2008) Depositional gaps in Abitibi greenstone belt stratigraphy: a key to exploration for syngenetic mineralization. Economic Geology 103, 1097-1134.

Tolstikhin, I.N., Skiba, V.I., Sevost'yanov, A.Y., Kamensky, I.L. and Vetrin, V.R. (2014) Residence sites and origin of noble gases in minerals as exemplified by ilmenite from the alkaline granites of the Kola Peninsula. Geochemistry International 52, 1049-1056.

Townend, J. and Zoback, M.D. (2000) How faulting keeps the crust strong. Geology 28, 399402.

Ward, J.A., Slater, G.F., Moser, D.P., Lin, L.H., Lacrampe-Couloume, G., Bonin, A.S., Davidson, M., Hall, J.A., Mislowack, B., Bellamy, R.E.S., Onstott, T.C. and Sherwood Lollar, B. (2004) Microbial hydrocarbon gases in the Witwatersrand Basin, South Africa: Implications for the deep biosphere. Geochimica Et Cosmochimica Acta 68, 3239-3250.

Warr, O., Rochelle, C.A., Masters, A. and Ballentine, C.J. (2015) Determining noble gas partitioning within a $\mathrm{CO}_{2}-\mathrm{H}_{2} \mathrm{O}$ system at elevated temperatures and pressures. Geochimica et Cosmochimica Acta 159, 112-125.

Wetherill, G.W. (1954) Variations in the isotopic abundances of neon and argon extracted from radioactive minerals. Physical Review 96, 679-683.

Figures

Figure 1. Location map of Kidd Creek Mine in Timmins and Mines 1 \& 2 in the Sudbury Basin. Latitude \& Longitude of each mine are as follows; Kidd Creek Mine: $48^{\circ} 41^{\prime} 24^{\prime \prime}$ North, $81^{\circ} 22^{\prime}$ 


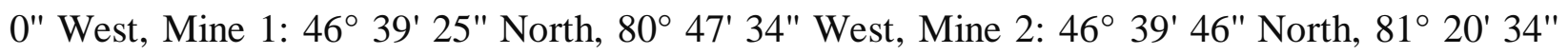
West.

Figure 2. Average isotopic ratios from each locality relative to ${ }^{36} \mathrm{Ar}$. The dashed line at 1 is the isotopic ratio for Air Saturated Water (ASW). ASW ratios given here are derived from seawater at $10{ }^{\circ} \mathrm{C}$ (Kipfer et al., 2002).

Figure 3. Comparison of neon isotopic ratios for samples from this and previous study. Data presented are $2.4 \mathrm{~km}$ samples from this work (black squares) and the 2013 study (blue squares), $2.9 \mathrm{~km}$ (red circles), Sudbury Mine 1 (green diamonds) and Mine 2 (gold star). Also given is the Air Saturated Water (ASW) value (orange cross), the mantle (solar) composition (blue cross, Graham, 2002). The two mixing lines shown for mixing between ASW and typical crustal radiogenic ${ }^{21} \mathrm{Ne} /{ }^{22} \mathrm{Ne}$ end-members for the crust (black line - from Ballentine \& Burnard, 2002) and for mixing between ASW and an elevated ${ }^{21} \mathrm{Ne} /{ }^{22} \mathrm{Ne}$ end-member first defined by the fracture fluid and fluid inclusion data from the Archean-aged Witwatersrand Basin (red line Lippman-Pipke et al., 2011).

Figure 4. Xenon excesses over modern air (normalised to ${ }^{130} \mathrm{Xe}$ ). For each ${ }^{136} \mathrm{Xe}$ excess the relative fission spectra for uranium is plotted (dotted lines) which reaches good agreement with measured excesses for ${ }^{134} \mathrm{Xe},{ }^{132} \mathrm{Xe}$ and ${ }^{131} \mathrm{Xe}$. Fission values taken from Ballentine and Burnard, (2002) and references therein. Fissiogenic excesses were calculated by anchoring the ${ }^{238} U$ fission spectra to ${ }^{136} \mathrm{Xe}$ and calculating the expected corresponding ${ }^{131-134} \mathrm{Xe}$ excess.

Figure 5. Percentage deviations of ${ }^{124-129} \mathrm{Xe} /{ }^{130} \mathrm{Xe}$ in samples compared to modern atmospheric ratios. Values plotted are averages for each isotope per sampling level at each mine (Table 8). 
The average percentage fractionation line for the ${ }^{124-128} \mathrm{Xe}$ excesses (dashed lines) was calculated as follows: 1. All individual percentage excesses for ${ }^{124-128} \mathrm{Xe}$ for each sample were divided by their respective mass difference from ${ }^{130} \mathrm{Xe}$ and an average excess per amu was calculated for each sample. 2. An average excess per amu was calculated for each sample. Lastly 3. Each average excess was multiplied by the mass difference from ${ }^{130} \mathrm{Xe}$ and plotted for each isotope. At Kidd Creek Mine, an additional ${ }^{129} \mathrm{Xe}$ excess is observed as described in Section 5.3, but not seen in the Sudbury Basin samples.

Figure 6. Mean residence time estimates based on radiogenic noble gas accumulation, presented graphically for all samples and compared to results from Holland et al. (2013). For context the last known major metasomatic event at Kidd Creek Mine, and the timing of the Sudbury bolide impact are also provided in the figure (Bleeker and Parrish, 1996; Davis, 2008). Analytical uncertainties for noble gas analysis are small. The large uncertainties for the error bars in this figure reflect minimum and maximum estimates in mean residence time estimates based on uncertainty in bulk porosity estimates for crystalline rock (see text) and are used to provide the most conservative possible sense of the mean residence time ranges derived from the data. Where analytical uncertainty exceeds known geological age, the upper limits of uncertainty have been restricted accordingly.

Figure 7. Schematic diagram outlining conceptual model for fractures within crystalline basement rock.

Figure 8. $\delta^{18} \mathrm{O} \& \delta^{2} \mathrm{H}$ values for fracture fluids at $2.4 \mathrm{~km}$ for ${ }^{1}$ the original study and ${ }^{2}$ resampled fluids (this work). Values are given in Table 10. All values remain significantly elevated above the Global Meteoric Water Line with no isotopic evolution over time. This indicates the less old fluid present in the later samples has undergone a comparable extensive water-rock interaction 
and therefore rules out the presence of recent meteoric water. Faded symbols for Kidd Creek Mine $2.9 \mathrm{~km} \&$ Sudbury are supplementary values from additional sample suites (Frape et al., 1984; Li et al., 2016) which highlight the consistency of the noble gas-associated values with the rest of the ${ }^{2} \mathrm{H} \&{ }^{18} \mathrm{O}$ data (with no evidence of their movement towards the GMWL).

\section{Tables}

\begin{tabular}{|c|c|c|c|}
\hline Borehole & Date & Fluid flow $(\mathrm{ml} / \mathrm{min})$ & Gas flow $\left(\mathrm{cm}^{3} / \mathrm{min}\right)$ \\
\hline \multicolumn{4}{|c|}{ Kidd Creek Mine (2.4 km) } \\
\hline 12287 & 20.09 .13 & N.M. & variable \\
\hline 12299 & 03.04 .14 & 180 & 300 \\
\hline \multicolumn{4}{|c|}{ Kidd Creek Mine (2.9 km) } \\
\hline 13684 & 01.03 .12 & $*$ & 1760 \\
\hline 13684 & 14.06 .12 & $*$ & 1200 \\
\hline $\mathrm{BH} 2$ & 29.11 .12 & N.M & 3600 \\
\hline $\mathrm{BH} 2$ & 16.01 .13 & N.M. & 1000 \\
\hline \multicolumn{4}{|c|}{ Sudbury Mine 1 (1.7 km) } \\
\hline 170128 & 29.11 .13 & 2390 & 2000 \\
\hline 170128 & 05.03 .14 & 2140 & $410-1200$ \\
\hline 170128 & 22.10 .14 & 2060 & $170-420$ \\
\hline \multicolumn{4}{|c|}{ Sudbury Mine $2(1.4$ km) } \\
\hline 47774 & 06.03 .14 & 2830 & 1130 \\
\hline
\end{tabular}

Table 1. Locations, dates and flow rates of samples collected from each locality. Dates are presented in DD/MM/YY format. Flowrates given in $\mathrm{ml} / \mathrm{min}$ and $\mathrm{cm}^{3} / \mathrm{min}$ for water and gas respectively. N.M. indicates not measured. * indicates standing water only, no artesian flow. Depth of level below land surface is also provided. 


\begin{tabular}{|c|c|c|c|c|c|c|c|c|}
\hline Sample & ${ }^{20} \mathrm{Ne}$ & error & ${ }^{36} \mathrm{Ar}$ & error & ${ }^{84} \mathrm{Kr}$ & error & ${ }^{130} \mathrm{Xe}$ & error \\
\hline Air & $1.65 \mathrm{E}-05$ & & $3.14 \mathrm{E}-05$ & & $6.50 \mathrm{E}-07$ & & $3.54 \mathrm{E}-09$ & \\
\hline \multicolumn{9}{|c|}{ Kidd Mine } \\
\hline \multicolumn{9}{|l|}{$(2.4$ km) } \\
\hline 12287 & $1.71 \mathrm{E}-08$ & $0.01 \mathrm{E}-08$ & $2.22 \mathrm{E}-07$ & $0.02 \mathrm{E}-07$ & $5.79 \mathrm{E}-09$ & $0.07 E-09$ & $6.46 \mathrm{E}-11$ & $0.10 \mathrm{E}-11$ \\
\hline 12299 & $5.40 \mathrm{E}-08$ & $0.05 E-08$ & $3.23 \mathrm{E}-07$ & $0.03 E-07$ & $9.00 \mathrm{E}-09$ & $0.11 E-09$ & $8.85 \mathrm{E}-11$ & $0.14 \mathrm{E}-11$ \\
\hline Average & $3.55 E-08$ & $2.61 \mathrm{E}-08$ & 2.73E-07 & $0.71 E-07$ & 7.4E-09 & 2.27E-09 & $7.66 \mathrm{E}-11$ & $1.69 \mathrm{E}-11$ \\
\hline \multicolumn{9}{|c|}{ Kidd Mine } \\
\hline \multicolumn{9}{|l|}{$(2.9 \mathrm{~km})$} \\
\hline 13684 & $6.74 \mathrm{E}-09$ & $0.06 \mathrm{E}-09$ & $2.65 \mathrm{E}-08$ & $0.05 \mathrm{E}-08$ & $7.09 \mathrm{E}-10$ & $0.08 \mathrm{E}-10$ & $8.17 \mathrm{E}-12$ & $0.12 \mathrm{E}-12$ \\
\hline 13684 & $9.02 \mathrm{E}-09$ & $0.08 \mathrm{E}-09$ & $2.28 \mathrm{E}-08$ & $0.05 \mathrm{E}-08$ & 7.99E-10 & $0.10 \mathrm{E}-10$ & $9.09 \mathrm{E}-12$ & $0.13 \mathrm{E}-12$ \\
\hline BH2 & 8.42E-09 & $0.09 \mathrm{E}-09$ & $2.66 \mathrm{E}-08$ & $0.07 E-08$ & $8.76 \mathrm{E}-10$ & $0,11 \mathrm{E}-10$ & $1.11 \mathrm{E}-11$ & $0.02 \mathrm{E}-11$ \\
\hline BH2 & $1.03 E-08$ & $0.01 E-08$ & 3.07E-08 & $0.13 \mathrm{E}-08$ & $9.26 \mathrm{E}-10$ & $0.11 \mathrm{E}-10$ & $1.17 \mathrm{E}-11$ & $0.02 \mathrm{E}-11$ \\
\hline Average & $8.62 E-09$ & $1.49 \mathrm{E}-09$ & $2.67 E-08$ & $0.32 \mathrm{E}-08$ & $8.28 \mathrm{E}-10$ & $0.94 \mathrm{E}-10$ & $1.00 E-11$ & $0.17-11$ \\
\hline \multicolumn{9}{|c|}{ Sudbury Mine 1} \\
\hline \multicolumn{9}{|l|}{$(1.7$ km) } \\
\hline 170128 & 7.93E-07 & $0.08 \mathrm{E}-07$ & $4.89 \mathrm{E}-06$ & $0.05 E-06$ & $1.41 \mathrm{E}-07$ & $0.02 E-07$ & $1.09 \mathrm{E}-09$ & $0.02 \mathrm{E}-09$ \\
\hline 170128 & $6.15 \mathrm{E}-07$ & $0.05 \mathrm{E}-07$ & $4.12 \mathrm{E}-06$ & $0.04 \mathrm{E}-06$ & $1.26 \mathrm{E}-07$ & $0.02 E-07$ & $1.02 \mathrm{E}-09$ & $0.02 \mathrm{E}-09$ \\
\hline 170128 & $6.59 \mathrm{E}-07$ & $0.07 E-07$ & $6.92 \mathrm{E}-06$ & $0.07 E-06$ & $2.15 \mathrm{E}-07$ & $0.03 E-07$ & $1.75 \mathrm{E}-09$ & $0.03 \mathrm{E}-09$ \\
\hline Average & $6.89 E-07$ & $0.93 E-07$ & $5.31 E-06$ & $1.45 \mathrm{E}-06$ & $1.61 \mathrm{E}-07$ & $0.48 E-08$ & $1.29 \mathrm{E}-09$ & $0.40 \mathrm{E}-09$ \\
\hline \multicolumn{9}{|c|}{ Sudbury Mine 2} \\
\hline \multicolumn{9}{|l|}{$(1.4$ km) } \\
\hline 47774 & $3.31 \mathrm{E}-0$ & $0.03 E-07$ & $3.72 \mathrm{E}-06$ & $0.04 \mathrm{E}-06$ & $1.11 \mathrm{E}-07$ & $0.01 \mathrm{E}-07$ & $1.01 \mathrm{E}-09$ & $0.02 \mathrm{E}-09$ \\
\hline Average & $3.31 \mathrm{E}-07$ & $0.03 E-07$ & 3.72E-06 & $0.04 \mathrm{E}-06$ & 1.11E-07 & $0.01 E-07$ & $1.01 \mathrm{E}-09$ & $0.02 E-09$ \\
\hline
\end{tabular}

Table 2. Concentrations of non-radiogenic noble gas isotopes in gas samples. Values given in $\mathrm{cm}^{3}$ per $\mathrm{cm}^{3}$ of gas under STP conditions to three significant figures. Isotopes presented here represent non-radiogenic noble gas isotopes which are present in the geological system, that is, atmospheric-derived noble gas naturally occurring in the groundwaters due to water which had equilibrated with atmospheric noble gases at the time of recharge. For each level both individual samples and an average concentration are presented. For each average value the error 
incorporates the standard deviation $(1 \sigma)$ of each individual measurement. Air values (compiled by (Ozima and Podosek, 2002) have been given for reference.

\begin{tabular}{|c|c|c|c|c|c|c|c|c|}
\hline Sample & ${ }^{20} \mathrm{Ne}$ & error & ${ }^{36} \mathrm{Ar}$ & error & ${ }^{84} \mathrm{Kr}$ & error & ${ }^{130} \mathrm{Xe}$ & error \\
\hline ASW & $1.48 \mathrm{E}-07$ & & $1.01 \mathrm{E}-06$ & & $4.00 \mathrm{E}-08$ & & $5.21 \mathrm{E}-10$ & \\
\hline \multicolumn{9}{|c|}{ Kidd Mine } \\
\hline \multicolumn{9}{|l|}{$(2.4 \mathrm{~km})$} \\
\hline 12287 & $7.74 \mathrm{E}-08$ & $0.06 \mathrm{E}-08$ & $1.01 \mathrm{E}-06$ & $0.01 \mathrm{E}-06$ & $2.63 \mathrm{E}-08$ & $0.03 E-08$ & $2.93 \mathrm{E}-10$ & $0.05 \mathrm{E}-10$ \\
\hline 12299 & $1.69 \mathrm{E}-07$ & $0.02 \mathrm{E}-07$ & $1.01 \mathrm{E}-06$ & $0.01 E-06$ & $2.81 \mathrm{E}-08$ & $0.03 E-08$ & $2.76 \mathrm{E}-10$ & $0.04 \mathrm{E}-10$ \\
\hline Average & $1.23 \mathrm{E}-07$ & $0.65 \mathrm{E}-07$ & $1.01 \mathrm{E}-06$ & $0.00 \mathrm{E}+00$ & $2.72 \mathrm{E}-08$ & $0.13 E-08$ & $2.85 E-10$ & $0.12 \mathrm{E}-10$ \\
\hline \multicolumn{9}{|c|}{ Kidd Mine } \\
\hline \multicolumn{9}{|l|}{$(2.9 \mathrm{~km})$} \\
\hline 13684 & $2.57 \mathrm{E}-07$ & $0.02 E-07$ & $1.01 \mathrm{E}-06$ & $0.02 E-08$ & $2.70 \mathrm{E}-08$ & $0.03 E-08$ & $3.11 \mathrm{E}-10$ & $0.05 E-10$ \\
\hline 13684 & 3.99E-07 & $0.03 E-07$ & $1.01 \mathrm{E}-06$ & $0.02 E-08$ & $3.54 \mathrm{E}-08$ & $0.04 \mathrm{E}-08$ & 4.03E-10 & $0.06 \mathrm{E}-10$ \\
\hline $\mathrm{BH} 2$ & $3.19 E-07$ & $0.04 \mathrm{E}-07$ & $1.01 \mathrm{E}-06$ & $0.02 \mathrm{E}-08$ & $3.32 \mathrm{E}-08$ & $0.04 \mathrm{E}-08$ & 4.19E-10 & $0.06 \mathrm{E}-10$ \\
\hline $\mathrm{BH} 2$ & $3.39 E-07$ & $0.03 E-07$ & $1.01 \mathrm{E}-06$ & $0.04 \mathrm{E}-08$ & $3.04 \mathrm{E}-08$ & $0.04 \mathrm{E}-08$ & $3.85 \mathrm{E}-10$ & $0.06 \mathrm{E}-10$ \\
\hline Average & 3.29E-07 & $0.59 \mathrm{E}-07$ & 1.01E-06 & $0.00 \mathrm{E}+00$ & $3.15 E-08$ & $0.36 \mathrm{E}-08$ & 3.79E-10 & $0.48 \mathrm{E}-10$ \\
\hline \multicolumn{9}{|c|}{ Sudbury Mine 1} \\
\hline \multicolumn{9}{|l|}{$(1.7$ km) } \\
\hline 170128 & $1.64 \mathrm{E}-07$ & $0.02 \mathrm{E}-07$ & $1.01 \mathrm{E}-06$ & $0.01 E-06$ & $2.92 \mathrm{E}-08$ & $0.04 \mathrm{E}-08$ & $2.26 \mathrm{E}-10$ & $0.04 \mathrm{E}-10$ \\
\hline 170128 & $1.51 \mathrm{E}-07$ & $0.01 E-07$ & $1.01 \mathrm{E}-06$ & $0.01 E-06$ & $3.08 \mathrm{E}-08$ & $0.04 \mathrm{E}-08$ & $2.49 \mathrm{E}-10$ & $0.04 \mathrm{E}-10$ \\
\hline 170128 & $9.61 \mathrm{E}-08$ & $0.10 \mathrm{E}-08$ & $1.01 \mathrm{E}-06$ & $0.01 E-06$ & $3.13 E-08$ & $0.04 \mathrm{E}-08$ & $2.55 \mathrm{E}-10$ & $0.04 \mathrm{E}-10$ \\
\hline Average & 1.37E-07 & $0.39 \mathrm{E}-07$ & $1.01 \mathrm{E}-06$ & $0.00 E+00$ & 3.04E-08 & $0.11 E-08$ & 2.43E-10 & $0.15 E-10$ \\
\hline \multicolumn{9}{|c|}{ Sudbury Mine 2} \\
\hline 47774 & $8.98 \mathrm{E}-08$ & $0.08 \mathrm{E}-08$ & $1.01 \mathrm{E}-06$ & 0.01E-06 & $3.00 \mathrm{E}-08$ & $0.04 \mathrm{E}-08$ & $2.75 \mathrm{E}-10$ & $0.04 \mathrm{E}-10$ \\
\hline Average & 8.98E-08 & $0.08 \mathrm{E}-08$ & $1.01 \mathrm{E}-06$ & $0.00 \mathrm{E}+00$ & $3.00 \mathrm{E}-08$ & $0.04 E-08$ & 2.75E-10 & $0.04 E-10$ \\
\hline
\end{tabular}

Table 3. Concentrations of non-radiogenic noble gas isotopes expressed per $\mathrm{cm}^{3}$ of fracture fluid to three significant figures. Concentrations are calculated by dividing the concentration per $\mathrm{cm}^{3}$ of gas by the total amount of water which has been degassed. Degassed water volume is derived 
assuming a ${ }^{36} \mathrm{Ar}$ content of $1.01 \times 10^{-6} \mathrm{~cm}^{3} / \mathrm{cm}^{3}$ of water based on concentrations in seawater at $10^{\circ} \mathrm{C}$ after the methods of (Kipfer et al., 2002). For each level both individual samples and an average concentration is presented. The error on the average value incorporates the standard deviation $(1 \sigma)$. Air Saturated seawater at $10^{\circ} \mathrm{C}$ are provided for reference (Kipfer et al., 2002). 


\begin{tabular}{|c|c|c|c|c|c|c|c|c|c|c|}
\hline \multirow{2}{*}{$\begin{array}{l}\text { Sample } \\
\text { Air/ASW }\end{array}$} & \multirow{2}{*}{$\begin{array}{l}{ }^{3} \mathrm{He} /{ }^{4} \mathrm{He} \\
\left(\mathrm{R} / \mathrm{R}_{\mathrm{A}}\right) \\
1.0000\end{array}$} & \multirow[t]{2}{*}{ error } & \multicolumn{5}{|c|}{${ }^{20} \mathrm{Ne} /{ }^{22} \mathrm{Ne}$ error ${ }^{21} \mathrm{Ne} /{ }^{22} \mathrm{Ne}$} & error & ${ }^{38} \mathrm{Ar} /{ }^{36} \mathrm{Ar}$ & \multirow[t]{2}{*}{ error } \\
\hline & & & 9.80 & & 0.029 & & 295.5 & & $1.880 \mathrm{E}-01$ & \\
\hline \multicolumn{11}{|c|}{$\begin{array}{l}\text { Kidd Mine } \\
(2.4 \mathrm{~km})\end{array}$} \\
\hline 12287 & 2.30E-02 & $0.07 \mathrm{E}-02$ & 8.64 & 0.02 & $2.861 \mathrm{E}-01$ & $0.002 \mathrm{E}-01$ & 16300 & 100 & $1.94 \mathrm{E}-01$ & 0.02 \\
\hline 12299 & $2.14 \mathrm{E}-02$ & $0.05 \mathrm{E}-02$ & 8.770 & 0.004 & 2.397E-01 & $0.001 \mathrm{E}-01$ & 13800 & 100 & $1.93 \mathrm{E}-01$ & 0.02 \\
\hline Average & $2.22 \mathrm{E}-02$ & $0.11 E-02$ & 8.71 & 0.09 & 2.63E-01 & 0.33 E-01 & 15100 & 1780 & $1.94 \mathrm{E}-01$ & 0.01 \\
\hline \multicolumn{11}{|c|}{$\begin{array}{l}\text { Kidd Mine } \\
(2.9 \mathrm{~km})\end{array}$} \\
\hline 13684 & $2.56 \mathrm{E}-02$ & $0.06 \mathrm{E}-02$ & 5.06 & 0.01 & 5.935E-01 & $0.002 \mathrm{E}-01$ & 77500 & 1270 & 2.25E-01 & $0.05 \mathrm{E}-01$ \\
\hline 13684 & 2.47E-02 & $0.06 \mathrm{E}-02$ & 5.27 & 0.02 & $5.722 \mathrm{E}-01$ & 0.003E-01 & 91000 & 1990 & 1.99E-01 & 0.09E-01 \\
\hline BH2 & $2.59 \mathrm{E}-02$ & $0.05 \mathrm{E}-02$ & 5.324 & 0.004 & 6.189E-01 & $0.002 \mathrm{E}-01$ & 116000 & 2680 & $2.28 \mathrm{E}-01$ & 0.07E-01 \\
\hline $\mathrm{BH} 2$ & 2.61E-02 & $0.05 E-02$ & 5.44 & 0.01 & $6.056 \mathrm{E}-01$ & $0.005 E-01$ & 125000 & 5230 & $1.83 \mathrm{E}-01$ & $0.12 \mathrm{E}-01$ \\
\hline Average & 2.56E-02 & $0.06 \mathrm{E}-02$ & 5.27 & 0.16 & $5.98 \mathrm{E}-01$ & $0.20 \mathrm{E}-01$ & 102000 & 22000 & 2.09E-01 & $0.22 \mathrm{E}-01$ \\
\hline \multicolumn{11}{|c|}{$\begin{array}{l}\text { Sudbury Mine } \\
1(1.7 \mathrm{~km})\end{array}$} \\
\hline 170128 & 1.96E-02 & $0.04 \mathrm{E}-02$ & 8.728 & 0.004 & $1.38 \mathrm{E}-01$ & $0.001 \mathrm{E}-01$ & 4330 & 5 & $1.912 \mathrm{E}-01$ & $0.005 \mathrm{E}-01$ \\
\hline 170128 & $1.95 \mathrm{E}-02$ & $0.04 \mathrm{E}-02$ & 8.772 & 0.004 & 1.39E-01 & $0.001 \mathrm{E}-01$ & 4430 & 6 & $1.954 \mathrm{E}-01$ & $0.004 \mathrm{E}-01$ \\
\hline 170128 & $1.95 \mathrm{E}-02$ & $0.04 \mathrm{E}-02$ & 8.88 & 0.01 & 1.37E-01 & $0.001 \mathrm{E}-01$ & 4310 & 4 & $1.918 \mathrm{E}-01$ & $0.005 E-01$ \\
\hline Average & $1.95 \mathrm{E}-02$ & $0.01 E-02$ & 8.79 & 0.08 & $1.38 \mathrm{E}-01$ & $0.01 E-01$ & 4350 & 63 & $1.93 \mathrm{E}-01$ & $0.02 E-01$ \\
\hline \multicolumn{11}{|c|}{$\begin{array}{l}\text { Sudbury Mine } \\
2(1.4 \mathrm{~km})\end{array}$} \\
\hline 47774 & $2.30 \mathrm{E}-02$ & 0.0005 & 7.960 & 0.002 & $1.324 \mathrm{E}-01$ & $0.001 E-01$ & 17600 & 82 & 1.97E-01 & $0.01 \mathrm{E}-01$ \\
\hline Average & $2.30 \mathrm{E}-2$ & 0.001 & 7.960 & 0.002 & $1.324 \mathrm{E}-01$ & $0.001 E-01$ & 17600 & 82 & 1.97E-01 & $0.01 E-01$ \\
\hline
\end{tabular}

Table 4. Noble gas isotope ratios for the sample suite given to three significant figures. Where the uncertainty is lower than the third significant figure an additional significant figure is given. For each level both individual samples and an average concentration is presented. The error on the average value is taken as the standard deviation $(1 \sigma)$. Helium ${ }^{3} \mathrm{He} /{ }^{4} \mathrm{He}$ ratios are given in $\mathrm{R} / \mathrm{R}_{\mathrm{A}}$ where $\mathrm{R}_{\mathrm{A}(\text { air })}=1$. Absolute ${ }^{3} \mathrm{He} /{ }^{4} \mathrm{He}($ air $)=$ $1.399 \times 10^{-6}$ (Mamyrin et al., 1970). Air/ASW values (compiled by (Ozima and Podosek, 2002) have been given for reference. 


\begin{tabular}{|c|c|c|c|c|c|c|c|c|}
\hline Sample & ${ }^{124} \mathrm{Xe} /{ }^{130} \mathrm{Xe}$ & error & ${ }^{126} \mathrm{Xe} /{ }^{130} \mathrm{Xe}$ & error & ${ }^{128} \mathrm{Xe} /{ }^{130} \mathrm{Xe}$ & error & ${ }^{129} \mathrm{Xe} /{ }^{130} \mathrm{Xe}$ & error \\
\hline Air/ASW & $2.34 \mathrm{E}-02$ & & $2.18 \mathrm{E}-02$ & & $4.72 \mathrm{E}-01$ & & 6.496 & \\
\hline \multicolumn{9}{|l|}{$\begin{array}{l}\text { Kidd Mine } \\
(2.4 \mathrm{~km})\end{array}$} \\
\hline 12287 & 2.37E-02 & 0.01E-02 & $2.18 \mathrm{E}-02$ & $0.01 E-02$ & 4.79E-01 & $0.02 \mathrm{E}-01$ & 6.56 & 0.03 \\
\hline 12299 & $2.37 \mathrm{E}-02$ & $0.02 \mathrm{E}-02$ & $2.18 \mathrm{E}-02$ & $0.02 \mathrm{E}-02$ & 4.74E-01 & 0.04E-01 & 6.61 & 0.04 \\
\hline Average & $2.370 \mathrm{E}-02$ & $0.003 E-02$ & $2.183 \mathrm{E}-02$ & $0.001 E-02$ & 4.76E-01 & $0.03 E-01$ & 6.58 & 0.03 \\
\hline \multicolumn{9}{|l|}{$\begin{array}{l}\text { Kidd Mine } \\
(2.9 \mathrm{~km})\end{array}$} \\
\hline 13684 & $2.40 \mathrm{E}-02$ & $0.01 \mathrm{E}-02$ & 2.19 E-02 & $0.01 \mathrm{E}-02$ & 4.82E-01 & $0.02 E-01$ & 6.72 & 0.02 \\
\hline 13684 & 2.39E-02 & $0.01 \mathrm{E}-02$ & $2.20 \mathrm{E}-02$ & $0.01 \mathrm{E}-02$ & 4.78E-01 & $0.02 E-01$ & 6.71 & 0.01 \\
\hline $\mathrm{BH} 2$ & $2.42 \mathrm{E}-02$ & $0.02 \mathrm{E}-02$ & $2.23 \mathrm{E}-02$ & 0.01E-02 & 4.86E-01 & $0.02 \mathrm{E}-01$ & 6.80 & 0.02 \\
\hline $\mathrm{BH} 2$ & $2.41 \mathrm{E}-02$ & $0.01 E-02$ & $2.23 \mathrm{E}-02$ & 0.01E-02 & 4.83E-01 & $0.02 E-01$ & 6.75 & 0.01 \\
\hline Average & 2.41E-02 & $0.01 E-02$ & $2.21 \mathrm{E}-02$ & $0.02 \mathrm{E}-02$ & $4.82 \mathrm{E}-01$ & $0.03 E-01$ & 6.75 & 0.04 \\
\hline \multicolumn{9}{|c|}{$\begin{array}{l}\text { Sudbury Mine } 1 \\
(1.7 \text { km) }\end{array}$} \\
\hline 170128 & 2.37E-02 & $0.01 E-02$ & 2.19 E-02 & $0.01 \mathrm{E}-02$ & 4.74E-01 & $0.02 \mathrm{E}-01$ & 6.52 & 0.03 \\
\hline 170128 & 2.37E-02 & $0.01 E-02$ & $2.19 \mathrm{E}-02$ & 0.01E-02 & 4.75E-01 & $0.02 \mathrm{E}-01$ & 6.53 & 0.03 \\
\hline 170128 & $2.35 \mathrm{E}-02$ & $0.01 E-02$ & $2.21 \mathrm{E}-02$ & $0.01 E-02$ & 4.76E-01 & $0.02 E-01$ & 6.51 & 0.03 \\
\hline Average & $2.36 \mathrm{E}-02$ & $0.01 E-02$ & $2.20 \mathrm{E}-02$ & $0.01 E-02$ & 4.75E-01 & 0.01E-01 & 6.52 & 0.01 \\
\hline \multicolumn{9}{|c|}{$\begin{array}{l}\text { Sudbury Mine } 2 \\
(1.4 \mathrm{~km})\end{array}$} \\
\hline 47774 & $2.34 \mathrm{E}-02$ & 0.01E-02 & $2.21 \mathrm{E}-02$ & $0.01 \mathrm{E}-02$ & 4.77E-01 & 0.03E-01 & 6.55 & 0.03 \\
\hline Average & 2.34E-02 & $0.01 E-02$ & $2.21 \mathrm{E}-02$ & $0.01 E-02$ & 4.77E-01 & $0.03 E-01$ & 6.55 & 0.03 \\
\hline Sample & ${ }^{131} \mathrm{Xe} /{ }^{130} \mathrm{Xe}$ & error & ${ }^{132} \mathrm{Xe} /{ }^{130} \mathrm{Xe}$ & error & ${ }^{134} \mathrm{Xe} /{ }^{130} \mathrm{Xe}$ & error & ${ }^{136} \mathrm{Xe} /{ }^{130} \mathrm{Xe}$ & error \\
\hline Air/ASW & 5.213 & & 6.607 & & 2.563 & & 2.176 & \\
\hline \multicolumn{9}{|l|}{$\begin{array}{l}\text { Kidd Mine } \\
(2.4 \mathrm{~km})\end{array}$} \\
\hline 12287 & 5.22 & 0.03 & 6.72 & 0.03 & 2.77 & 0.01 & 2.41 & 0.01 \\
\hline 12299 & 5.45 & 0.03 & 6.78 & 0.04 & 2.80 & 0.02 & 2.44 & 0.01 \\
\hline Average & 5.33 & 0.16 & 6.75 & 0.04 & 2.79 & 0.02 & 2.42 & 0.02 \\
\hline \multicolumn{9}{|l|}{$\begin{array}{l}\text { Kidd Mine } \\
(2.9 \mathrm{~km})\end{array}$} \\
\hline 13684 & 5.33 & 0.01 & 7.60 & 0.02 & 4.16 & 0.02 & 4.11 & 0.02 \\
\hline 13684 & 5.94 & 0.02 & 7.51 & 0.02 & 4.03 & 0.01 & 3.94 & 0.01 \\
\hline $\mathrm{BH} 2$ & 5.35 & 0.01 & 7.66 & 0.02 & 4.24 & 0.01 & 4.21 & 0.02 \\
\hline $\mathrm{BH} 2$ & 5.31 & 0.01 & 7.53 & 0.02 & 4.09 & 0.01 & 4.01 & 0.01 \\
\hline Average & 5.48 & 0.30 & 7.58 & 0.07 & 4.13 & 0.09 & 4.07 & 0.12 \\
\hline \multicolumn{9}{|c|}{$\begin{array}{l}\text { Sudbury Mine } 1 \\
(1.7 \mathrm{~km})\end{array}$} \\
\hline 170128 & 5.22 & 0.02 & 6.72 & 0.03 & 2.75 & 0.01 & 2.39 & 0.01 \\
\hline 170128 & 5.23 & 0.02 & 6.74 & 0.03 & 2.76 & 0.01 & 2.40 & 0.01 \\
\hline 170128 & 5.21 & 0.02 & 6.71 & 0.03 & 2.74 & 0.01 & 2.37 & 0.01 \\
\hline Average & 5.22 & 0.01 & 6.72 & 0.02 & 2.75 & 0.01 & 2.39 & 0.01 \\
\hline \multicolumn{9}{|c|}{$\begin{array}{l}\text { Sudbury Mine } 2 \\
(1.4 \text { km) }\end{array}$} \\
\hline 47774 & 5.27 & 0.03 & 7.08 & 0.04 & 3.27 & 0.02 & 3.00 & 0.02 \\
\hline Average & 5.27 & 0.03 & 7.08 & 0.04 & 3.27 & 0.02 & 3.00 & 0.02 \\
\hline
\end{tabular}


Table 5. Xenon noble gas isotope ratios for the sample suite given to three significant figures.

Where the uncertainty is lower than the third significant figure an additional significant figure is given. For each level both individual samples and an average concentration is presented. The error on the average value incorporates the standard deviation $(1 \sigma)$. Air values (compiled by (Ozima and Podosek, 2002) have been given for reference.

\begin{tabular}{|c|c|c|c|c|c|c|c|c|}
\hline Sample & ${ }^{4} \mathrm{He}^{*}$ & error & ${ }^{21} \mathrm{Ne}^{*}$ & error & ${ }^{40} \mathrm{Ar}^{*}$ & error & ${ }^{136} \mathrm{Xe}^{*}$ & error \\
\hline $\begin{array}{l}\text { Kidd Min } \\
(2.4 \mathrm{~km})\end{array}$ & & & & & & & & \\
\hline $\begin{array}{l}12287 \\
12299\end{array}$ & $\begin{array}{l}6.88 \mathrm{E}-02 \\
9.49 \mathrm{E}-02\end{array}$ & $\begin{array}{l}0.10 \mathrm{E}-02 \\
0.13 \mathrm{E}-02\end{array}$ & $\begin{array}{l}2.33 \mathrm{E}-09 \\
4.11 \mathrm{E}-09\end{array}$ & $\begin{array}{l}0.03 E-09 \\
0.05 E-09\end{array}$ & $\begin{array}{l}1.62 \mathrm{E}-02 \\
1.36 \mathrm{E}-02\end{array}$ & $\begin{array}{l}0.02 \mathrm{E}-02 \\
0.02 \mathrm{E}-02\end{array}$ & $\begin{array}{l}6.87 \mathrm{E}-11 \\
7.27 \mathrm{E}-11\end{array}$ & $\begin{array}{l}0.15 E-11 \\
0.17 E-11\end{array}$ \\
\hline Average & 8.19E-02 & $1.85 \mathrm{E}-02$ & 3.22E-09 & $1.26 \mathrm{E}-09$ & $1.49 \mathrm{E}-02$ & $0.18 \mathrm{E}-02$ & 7.07E-11 & $0.28 \mathrm{E}-11$ \\
\hline $\begin{array}{l}\text { Kidd Mir } \\
(2.9 \mathrm{~km})\end{array}$ & & & & & & & & \\
\hline 13684 & 6.69E-01 & 0.09E-01 & 2.93E-08 & $0.04 \mathrm{E}-08$ & 7.79E-02 & $0.16 \mathrm{E}-02$ & $6.02 \mathrm{E}-10$ & $0.13 \mathrm{E}-10$ \\
\hline 13684 & 8.65E-01 & $0.12 \mathrm{E}-01$ & 4.22E-08 & 0.05E-08 & $9.15 \mathrm{E}-02$ & $0.22 \mathrm{E}-02$ & 7.11E-10 & $0.15 E-10$ \\
\hline $\mathrm{BH} 2$ & 9.09E-01 & $0.13 E-01$ & $3.61 \mathrm{E}-08$ & $0.06 \mathrm{E}-08$ & 1.17E-01 & $0.03 \mathrm{E}-01$ & $8.51 \mathrm{E}-10$ & $0.18 \mathrm{E}-10$ \\
\hline BH2 & 7.47E-01 & $0.11 \mathrm{E}-01$ & 3.67E-08 & 0.04E-08 & $1.26 \mathrm{E}-01$ & $0.05 E-01$ & 7.06E-10 & $0.15 E-10$ \\
\hline Average & 7.97E-01 & 1.10E-01 & 3.61E-08 & 5.29E-09 & $1.03 E-01$ & $2.22 \mathrm{E}-02$ & 7.17E-10 & $1.03 E-10$ \\
\hline $\begin{array}{l}\text { Sudbury } \\
(1.7 \mathrm{~km})\end{array}$ & & & & & & & & \\
\hline 170128 & $6.96 \mathrm{E}-02$ & $0.10 \mathrm{E}-02$ & 2.11E-09 & 0.03E-09 & 4.07E-03 & $0.05 E-03$ & $4.81 \mathrm{E}-11$ & $0.11 \mathrm{E}-11$ \\
\hline 170128 & $5.88 \mathrm{E}-02$ & $0.09 E-02$ & 1.93E-09 & $0.02 \mathrm{E}-09$ & 4.17E-03 & $0.05 E-03$ & $5.48 \mathrm{E}-11$ & $0.12 \mathrm{E}-11$ \\
\hline 170128 & $3.95 \mathrm{E}-02$ & $0.06 \mathrm{E}-02$ & 1.20E-09 & 0.02E-09 & 4.05E-03 & $0.06 \mathrm{E}-03$ & 5.07E-11 & $0.12 \mathrm{E}-11$ \\
\hline Average & $5.60 \mathrm{E}-02$ & $1.53 \mathrm{E}-02$ & 1.75E-09 & $0.48 \mathrm{E}-09$ & 4.09E-03 & $0.06 \mathrm{E}-03$ & 5.12E-11 & $0.34 \mathrm{E}-11$ \\
\hline $\begin{array}{l}\text { Sudbury } \\
(1.4 \mathrm{~km})\end{array}$ & & \multicolumn{6}{|c|}{ Sudbury Mine 2} & \\
\hline 47774 & $2.79 \mathrm{E}-02$ & $0.04 \mathrm{E}-02$ & $1.23 \mathrm{E}-09$ & $0.02 \mathrm{E}-11$ & $1.75 \mathrm{E}-02$ & $0.02 \mathrm{E}-02$ & 2.27E-10 & $0.05 \mathrm{E}-10$ \\
\hline Average & 2.79E-02 & $0.04 \mathrm{E}-02$ & $1.23 \mathrm{E}-09$ & $0.02 E-11$ & $1.75 \mathrm{E}-02$ & $0.02 \mathrm{E}-02$ & 2.27E-10 & $0.05 E-10$ \\
\hline
\end{tabular}


Table 6. Concentrations of excess radiogenic noble gas isotopes expressed per $\mathrm{cm}^{3}$ of fracture fluid given to three significant figures. The method for deriving concentrations within the fracture fluid is outlined in the main text. Isotopes presented here represent radiogenic noble gas isotopes which have accumulated within the system over time due to naturally occurring radioactive decay of parent isotopes. In situ radiogenic noble gas concentrations are derived by multiplying the measured ratios (Tables $5 \& 6$ ) by non-radiogenic concentrations (Táble 3 ) and subtracting this from total concentrations of the radiogenic isotopes. For each level both individual samples and an average concentration is presented. The error on the average value incorporates the standard deviation $(1 \sigma)$.

\begin{tabular}{|c|c|c|c|c|c|c|c|c|}
\hline Sample & ${ }^{4} \mathrm{He}^{*}$ & error & ${ }^{21} \mathrm{Ne}^{*}$ & error & ${ }^{40} \mathrm{Ar}^{*}$ & error & ${ }^{136} \mathrm{Xe}^{*}$ & error \\
\hline \multicolumn{9}{|c|}{ Kidd Mine } \\
\hline \multicolumn{9}{|l|}{$(2.9$ km) } \\
\hline 13684 & 3.84E-01 & $0.05 E-01$ & $1.69 \mathrm{E}-08$ & $0.02 E-08$ & 7.79E-02 & $0.16 \mathrm{E}-02$ & $1.01 \mathrm{E}-09$ & 0.02E-09 \\
\hline 13684 & 3.19E-01 & $0.05 E-01$ & $1.56 \mathrm{E}-08$ & $0.02 \mathrm{E}-08$ & $9.15 \mathrm{E}-02$ & $0.23 \mathrm{E}-02$ & $9.20 \mathrm{E}-10$ & $0.19 \mathrm{E}-10$ \\
\hline BH2 & $4.21 \mathrm{E}-01$ & $0.06 \mathrm{E}-01$ & 1.67E-08 & 0.03E-08 & 1.17E-01 & $0.30 \mathrm{E}-02$ & 1.06E-09 & $0.02 E-09$ \\
\hline $\mathrm{BH} 2$ & $3.25 \mathrm{E}-01$ & $0.05 \mathrm{E}-01$ & $1.60 \mathrm{E}-08$ & $0.02 E-08$ & $1.26 \mathrm{E}-01$ & $0.55 \mathrm{E}-02$ & $9.55 \mathrm{E}-10$ & $0.20 \mathrm{E}-10$ \\
\hline Average & $3.58 \mathrm{E}-01$ & 0.49E-01 & $1.62 \mathrm{E}-08$ & $0.237 E-08$ & 1.03E-01 & $0.22 E-01$ & $9.85 \mathrm{E}-10$ & $1.41 E-10$ \\
\hline
\end{tabular}

Table 7. Corrected concentrations of excess radiogenic noble gas isotopes per $\mathrm{cm}^{3}$ of fracture fluid for Kidd Creek Mine at $2.9 \mathrm{~km}$ depth given to three significant figures. Excesses corrected for effect of Rayleigh degassing using ASW-derived component (see text). 


\begin{tabular}{|c|c|c|c|c|c|c|c|c|}
\hline Sample & ${ }^{124} \mathrm{Xe}(\%)$ & error & ${ }^{126} \mathrm{Xe}(\%)$ & error & ${ }^{128} \mathrm{Xe}(\%)$ & error & ${ }^{129} \mathrm{Xe}(\%)$ & error \\
\hline \multicolumn{9}{|c|}{ Kidd Mine } \\
\hline \multicolumn{9}{|l|}{$(2.4 \mathrm{~km})$} \\
\hline 12287 & 1.51 & 0.01 & 0.165 & 0.001 & 1.50 & 0.01 & 0.96 & 0.01 \\
\hline 12299 & 1.30 & 0.01 & 0.115 & 0.001 & 0.535 & 0.004 & 1.72 & 0.01 \\
\hline Average & 1.40 & 0.14 & 0.140 & 0.036 & 1.02 & 0.68 & 1.34 & 0.54 \\
\hline \multicolumn{9}{|c|}{ Kidd Mine } \\
\hline \multicolumn{9}{|l|}{$(2.9 \mathrm{~km})$} \\
\hline 13684 & 2.73 & 0.02 & 0.616 & 0.003 & 2.23 & 0.01 & 3.48 & 0.01 \\
\hline 13684 & 2.39 & 0.01 & 1.05 & 0.01 & 1.33 & 0.01 & 3.36 & 0.01 \\
\hline $\mathrm{BH} 2$ & 3.39 & 0.02 & 2.12 & 0.01 & 2.97 & 0.02 & 4.64 & 0.01 \\
\hline $\mathrm{BH} 2$ & 3.30 & 0.02 & 2.39 & 0.01 & 2.44 & 0.01 & 3.91 & 0.01 \\
\hline Average & 2.95 & 0.48 & 1.54 & 0.85 & 2.24 & 068 & 3.85 & 0.58 \\
\hline \multicolumn{9}{|c|}{ Sudbury Mine } \\
\hline \multicolumn{9}{|l|}{$1(1.7$ km) } \\
\hline 170128 & 1.62 & 0.01 & 0.563 & 0.003 & 0.613 & 0.003 & 0.315 & 0.001 \\
\hline 170128 & 1.34 & 0.01 & 0.536 & 0.003 & 0.626 & 0.002 & 0.537 & 0.002 \\
\hline 170128 & 0.51 & 0.003 & 1.22 & 0.01 & 0.887 & 0.004 & 0.204 & 0.001 \\
\hline Average & 1.16 & 0.57 & 0.772 & 0.386 & 0.709 & 0.154 & 0.352 & 0.170 \\
\hline \multicolumn{9}{|c|}{ Sudbury Mine } \\
\hline \multicolumn{9}{|l|}{$2(1.4$ km) } \\
\hline 47774 & 0.036 & 0.0002 & 1.45 & 0.01 & 1.09 & 0.01 & 0.768 & 0.004 \\
\hline
\end{tabular}

Table 8. Percentage deviations of ${ }^{124-129} \mathrm{Xe} /{ }^{130} \mathrm{Xe}$ in samples over modern atmospheric ratios given to three significant figures. Where the uncertainty is lower than the third significant figure an additional significant figure is given. Average values and the standard deviation are also provided. 


\section{ACCEPTED MANUSCRIPT}

\begin{tabular}{|c|c|c|c|c|c|c|c|c|c|c|}
\hline Sample location & ${ }^{4} \mathrm{He}$ Age & \pm & ${ }^{21} \mathrm{Ne}$ Age & \pm & ${ }^{40}$ Ar Age & \pm & ${ }^{136}$ Xe Age & \pm & Ave & \pm \\
\hline 12261 & 850 & 386 & 1340 & 609 & 971 & 439 & 1509 & 686 & 1168 & 309 \\
\hline $12299-1$ & 1493 & 678 & 1527 & 697 & 1396 & 632 & 1666 & 757 & 1521 & 112 \\
\hline $12299-2$ & 951 & 432 & 1594 & 728 & 999 & 453 & 1321 & 601 & 1216 & 301 \\
\hline $12299-3$ & 1142 & 515 & 1570 & 720 & 1095 & 496 & 1613 & 731 & 1355 & 274 \\
\hline $12287-2$ & 666 & 303 & 1174 & 538 & 884 & 400 & 919 & 418 & 911 & 208 \\
\hline Kidd Mine $(2.4 \mathrm{~km})^{1}$ & 1026 & 577 & 1443 & 683 & 1078 & 559 & 1411 & 719 & 1240 & 218 \\
\hline 12287 & 482 & 219 & 166 & 75 & 638 & 288 & 149 & 68 & 359 & 241 \\
\hline 12299 & 658 & 298 & 290 & 132 & 552 & 249 & 157 & 71 & 414 & 231 \\
\hline Kidd Mine $(2.4 \mathrm{~km})^{2}$ & 570 & 289 & 228 & 136 & 595 & 278 & 153 & 70 & 387 & 229 \\
\hline 13684 & 2149 & 975 & 1024 & 464 & 1884 & 850 & 1763 & 800 & 1705 & 482 \\
\hline 13684 & 1834 & 832 & 951 & 431 & 2078 & 938 & 1627 & 738 & 1622 & 484 \\
\hline $\mathrm{BH} 2$ & 2316 & 1050 & 1015 & 460 & 2387 & 1077 & 1842 & 836 & 1890 & 632 \\
\hline $\mathrm{BH} 2$ & 1860 & 844 & 973 & 441 & 2493 & 1129 & 1683 & 764 & 1752 & 625 \\
\hline Kidd Mine (2.9 km) & 2023 & 959 & 986 & 470 & 2226 & 1112 & 1729 & 822 & 1741 & 543 \\
\hline 170128 & 790 & 389 & 245 & 121 & 224 & 101 & 171 & 84 & 357 & 290 \\
\hline 170128 & 671 & 331 & 225 & 111 & 229 & 103 & 194 & 96 & 330 & 228 \\
\hline 170128 & 456 & 225 & 140 & 69 & 222 & 100 & 180 & 89 & 250 & 142 \\
\hline Sudbury Mine 1 (1.7 km) & 640 & 360 & 204 & 115 & 225 & 101 & 182 & 90 & 313 & 219 \\
\hline 47774 & 344 & 170 & 153 & 75 & 850 & 383 & 828 & 408 & 544 & 350 \\
\hline Sudbury Mine $2(1.4 \mathrm{~km})$ & 344 & 170 & 153 & 75 & 850 & 383 & 828 & 408 & 544 & 350 \\
\hline
\end{tabular}

Table 9. Individual borehole and overall average ages for each sampling locality for each radiogenic isotope based on radiogenic excesses. Ages given in Ma. ${ }^{1}$ Represents the age of Kidd Mine at $2.4 \mathrm{~km}$ depth recalculated from Holland et al. (2013) using new estimates of bulk porosity as a function of depth and renormalizing to ${ }^{36} \mathrm{Ar}$ (Sherwood Lollar et al., 2014). ${ }^{2}$ Represents ages derived from samples taken from the same boreholes as the Holland et al. (2013) study 44 months later. Residence times are calculated from the average radiogenic excess per sample location (Tables 4 and 7). The observed uncertainty is primarily a result of poor constraints on the bulk porosity $( \pm 45 \%)$ rather than analytical uncertainty (1-2\%). 


\begin{tabular}{|c|c|c|c|c|}
\hline Sample location & $\delta^{18} \mathrm{O}$ & error & $\delta^{2} \mathrm{H}$ & error \\
\hline 12261 & -12.8 & 0.2 & -32.0 & 0.8 \\
\hline $12299-1$ & -12.8 & 0.2 & -38.6 & 0.8 \\
\hline $12299-2$ & -13.3 & 0.2 & -35.8 & 0.8 \\
\hline $12299-3$ & -13.5 & 0.2 & -36.7 & 0.8 \\
\hline $12287-2$ & -13.0 & 0.2 & -40.5 & 0.8 \\
\hline Kidd Mine $(2.4 \text { km })^{1}$ & -13.1 & 0.3 & -36.7 & 3.2 \\
\hline 12287 & -13.1 & 0.2 & -35.3 & 0.8 \\
\hline 12299 & -12.9 & 0.2 & -33.1 & 0.8 \\
\hline Kidd Mine $(2.4 \mathrm{~km})^{2}$ & -13.0 & 0.2 & -34.2 & 1.6 \\
\hline
\end{tabular}

Table 10. $\delta^{18} \mathrm{O} \& \delta^{2} \mathrm{H}$ values for fracture fluids at $2.4 \mathrm{~km}$ for ${ }^{1}$ the original study and ${ }^{2}$ resampled fluids (this work). Values are expressed as per mil (\%o) variations from Vienna Standard Mean Ocean Water (VSMOW). Errors for individual measurements are \pm 0.2 and $\pm 0.8 \%$ for $\delta^{18} \mathrm{O}$ and $\delta^{2} \mathrm{H}$ respectively. Analytical techniques are outlined in Appendix B. 


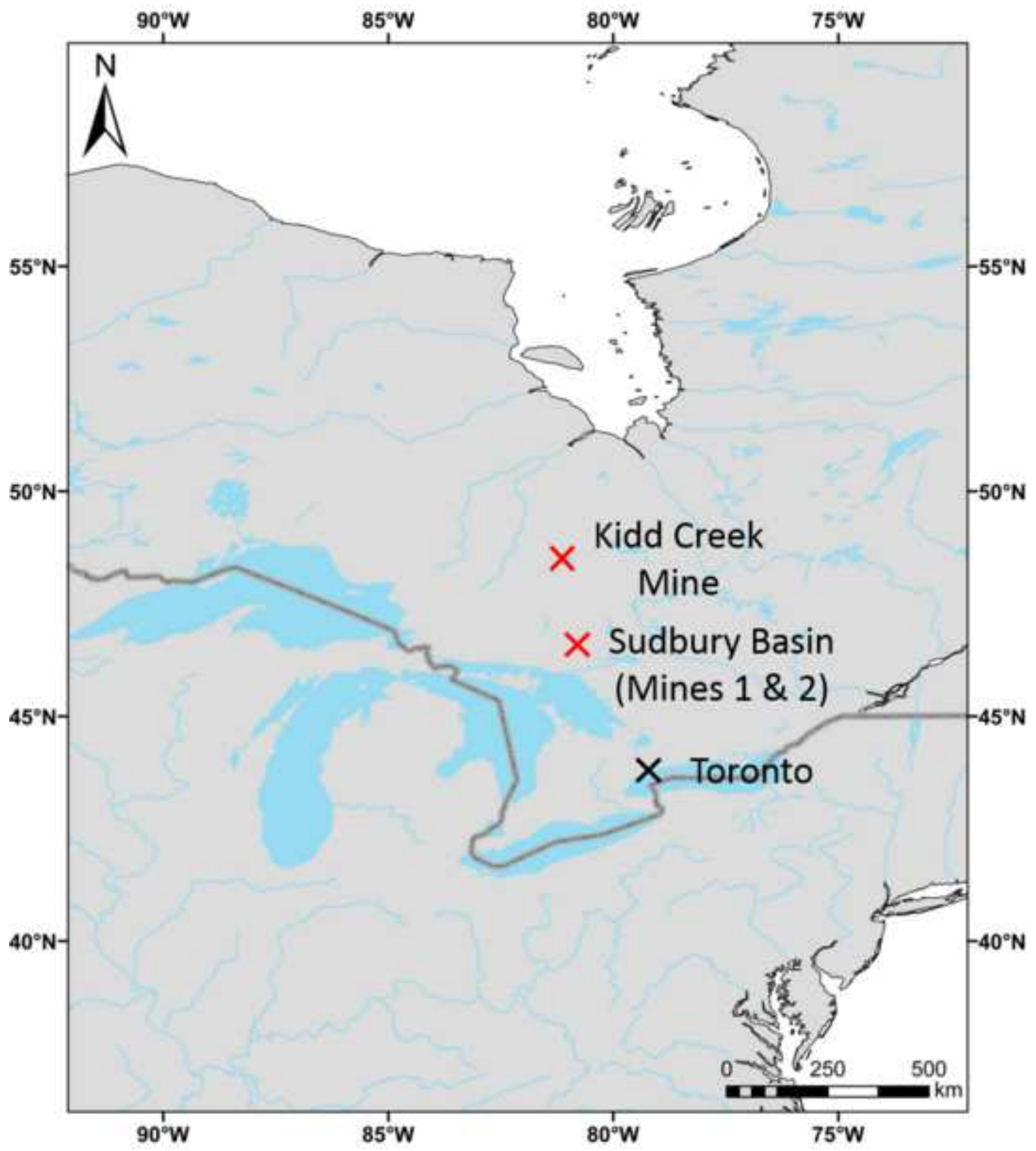




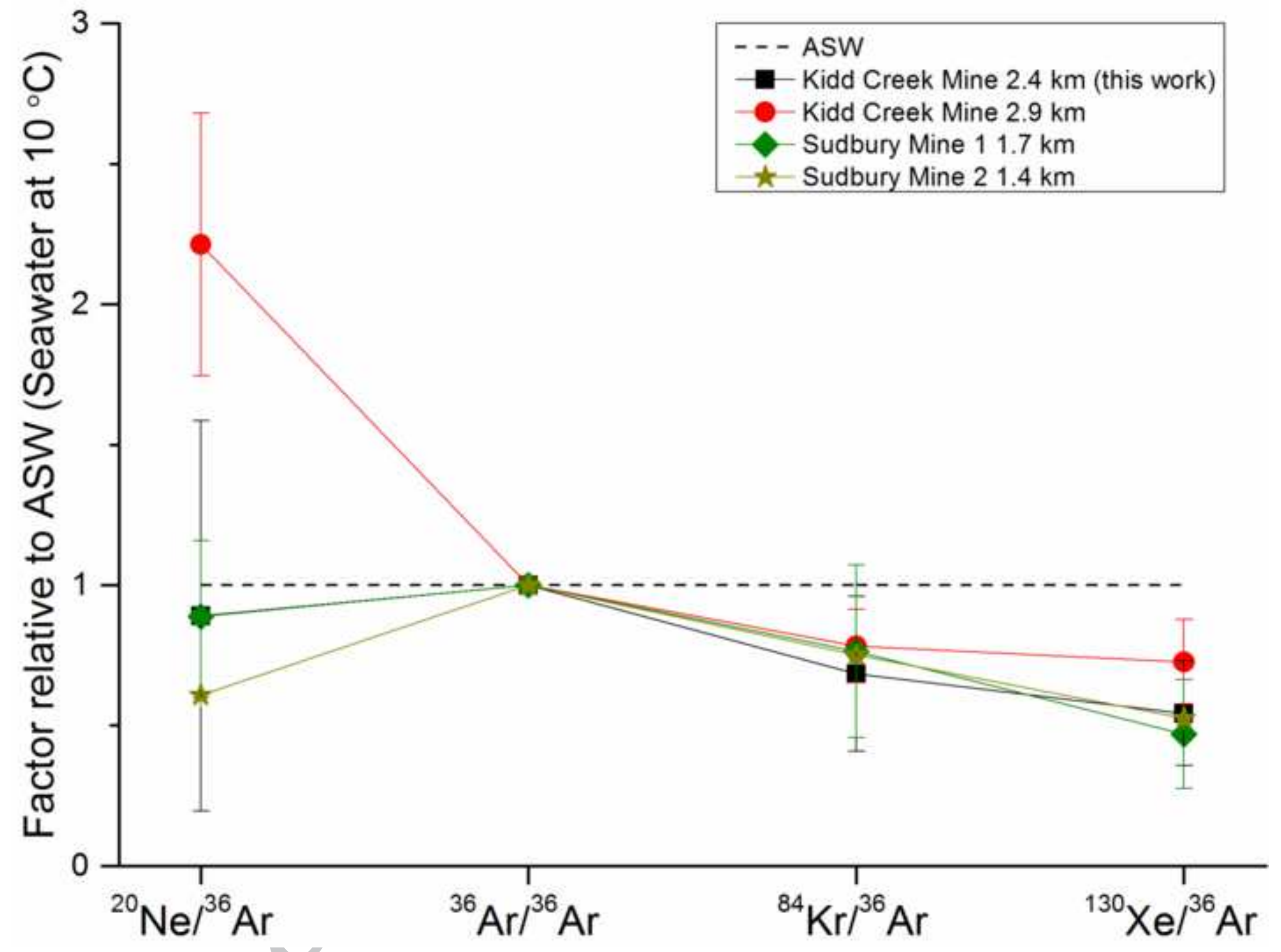




\section{ACCEPTED MANUSCRIPT}

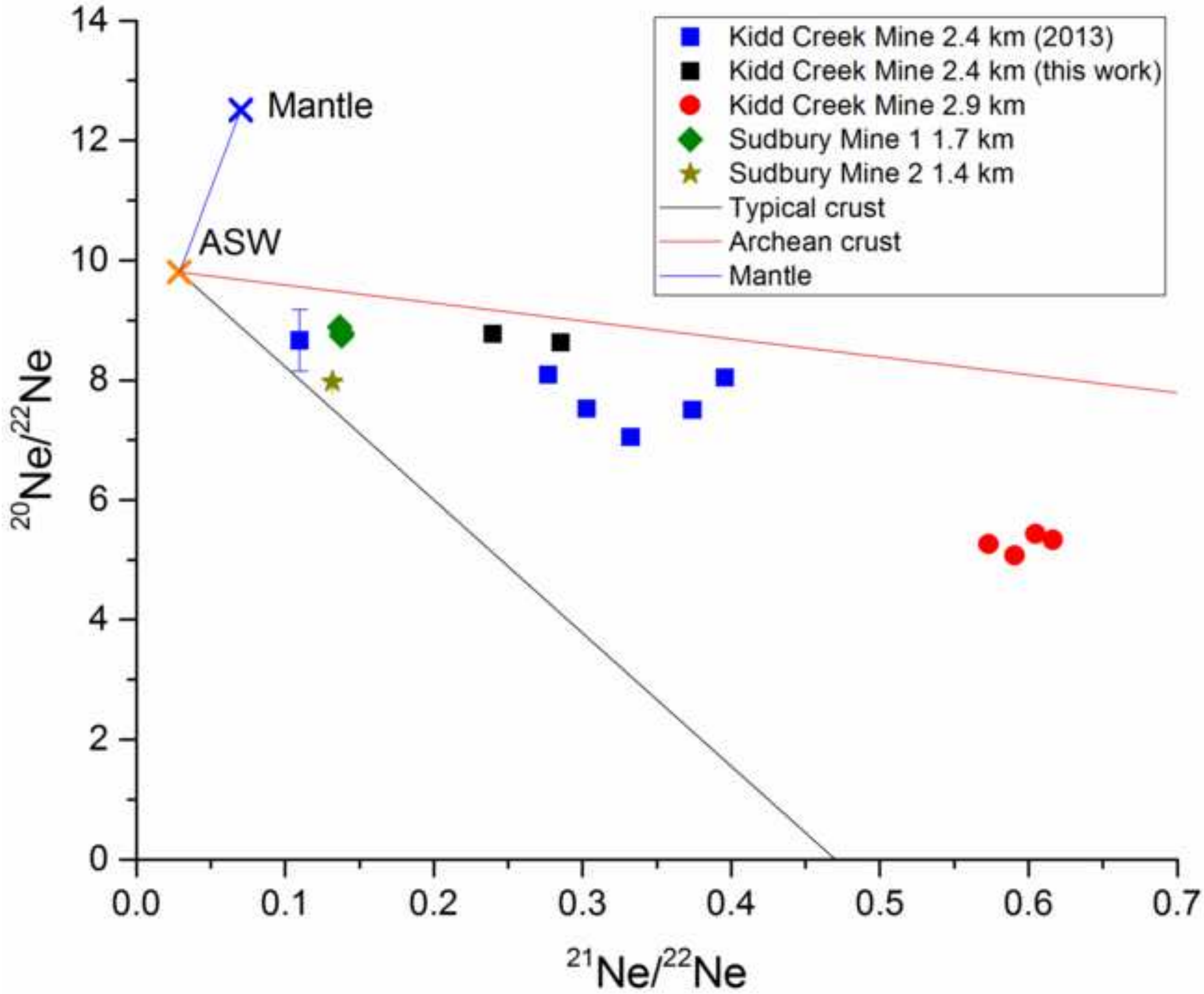




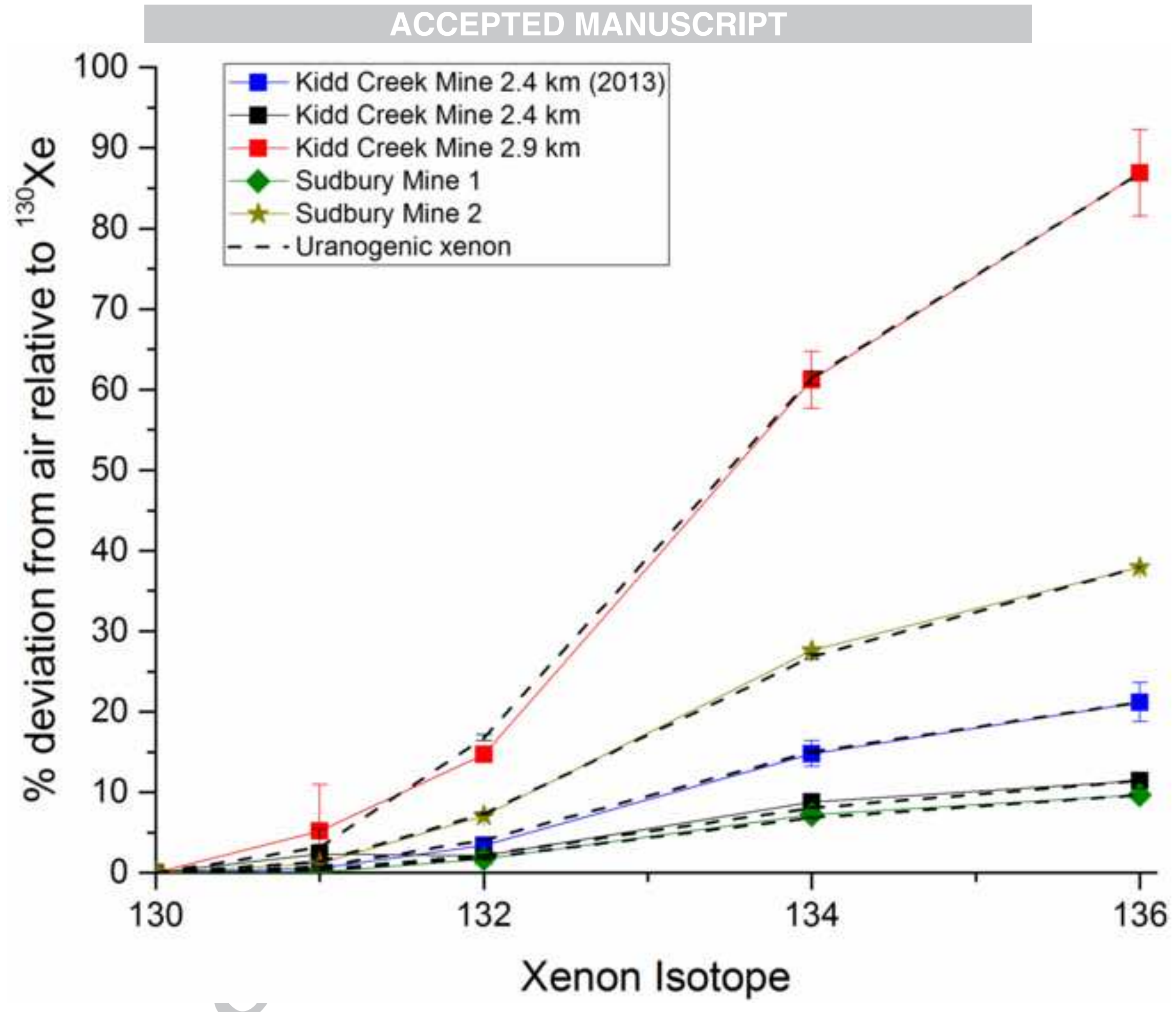




\section{ACCEPTED MANUSCRIPT}

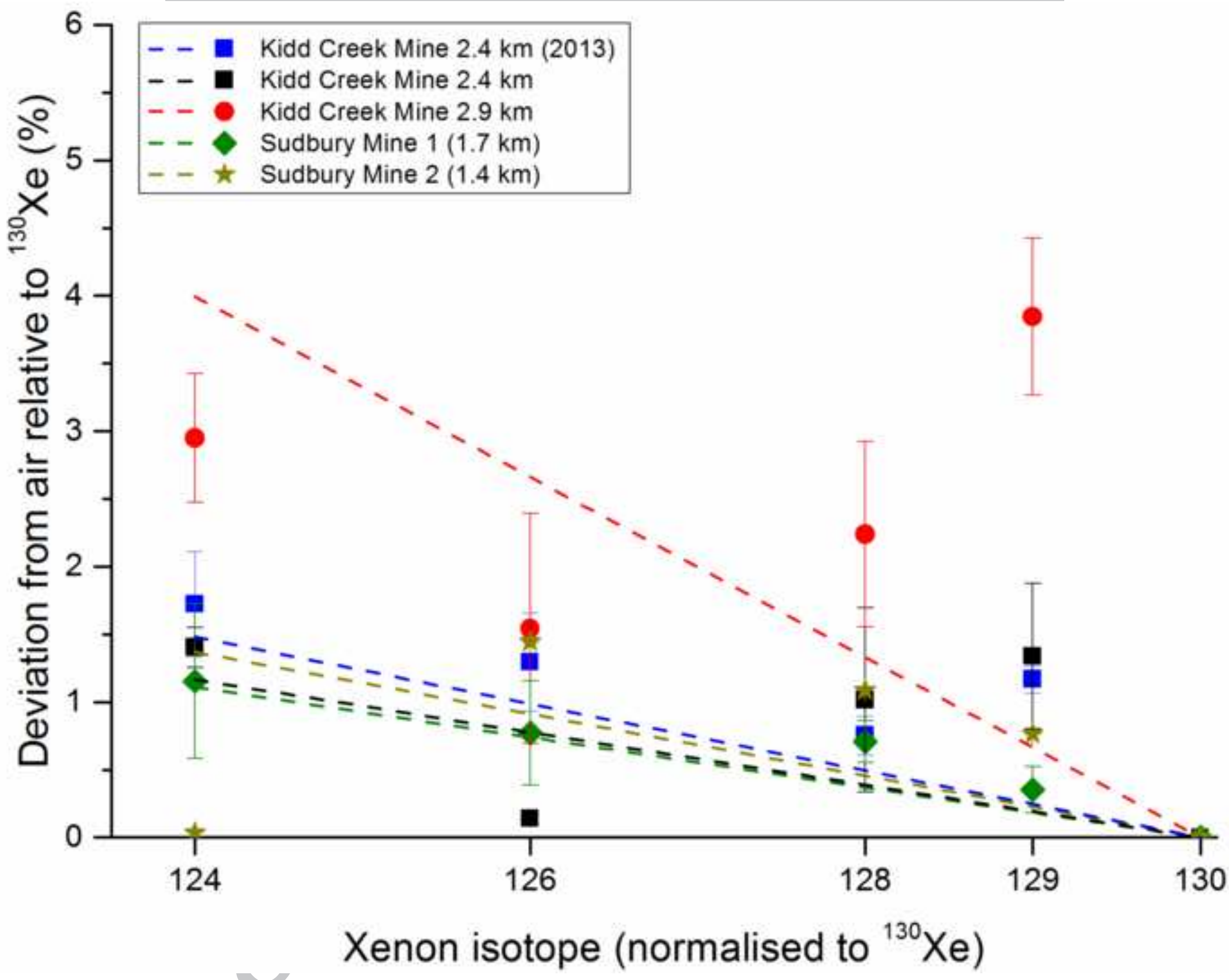




\section{ACCEPTED MANUSCRIPT}

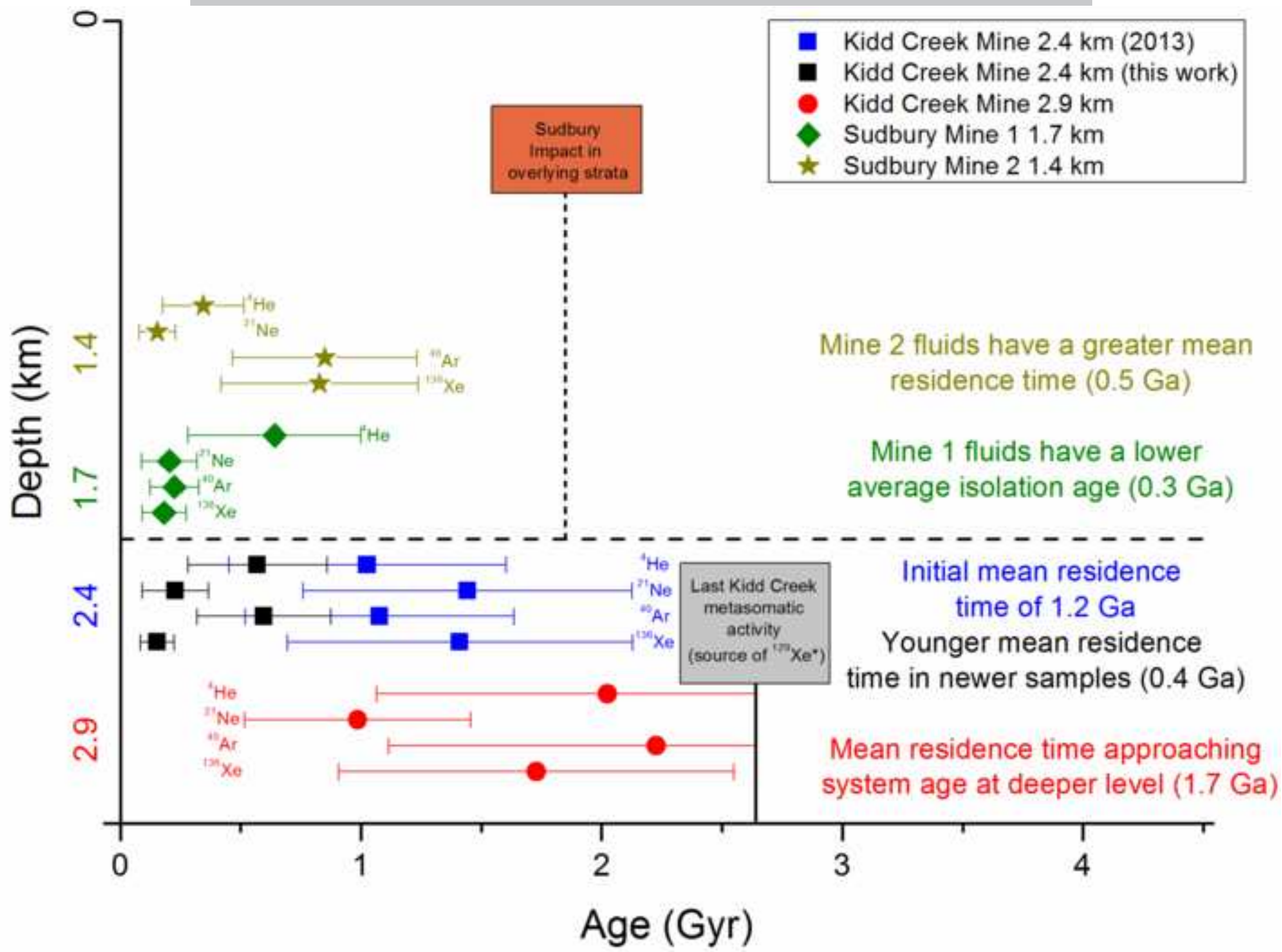




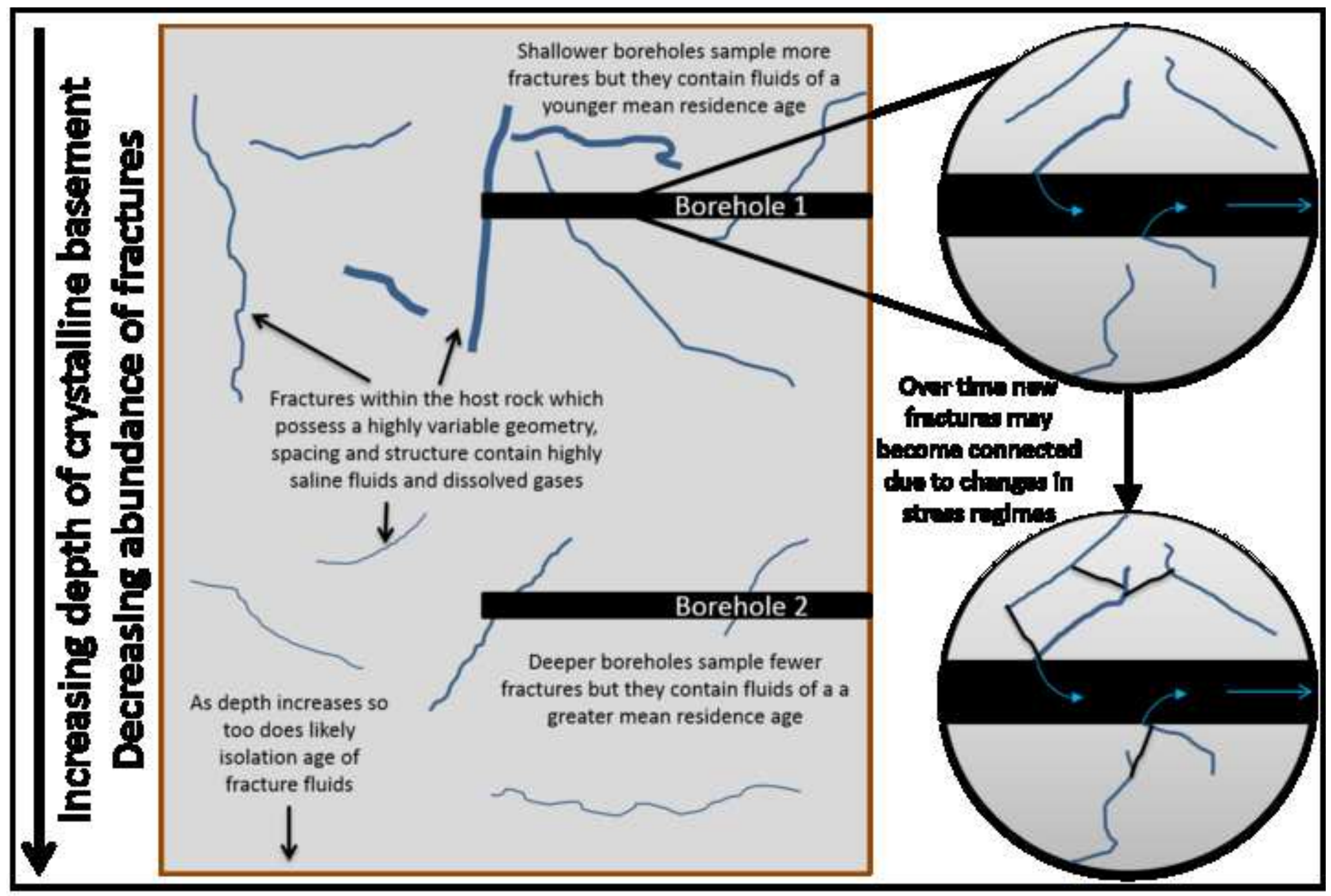

s depth increases so too does likely isolation age of acture fluids $\downarrow$ fractures but they contain fluids of a 


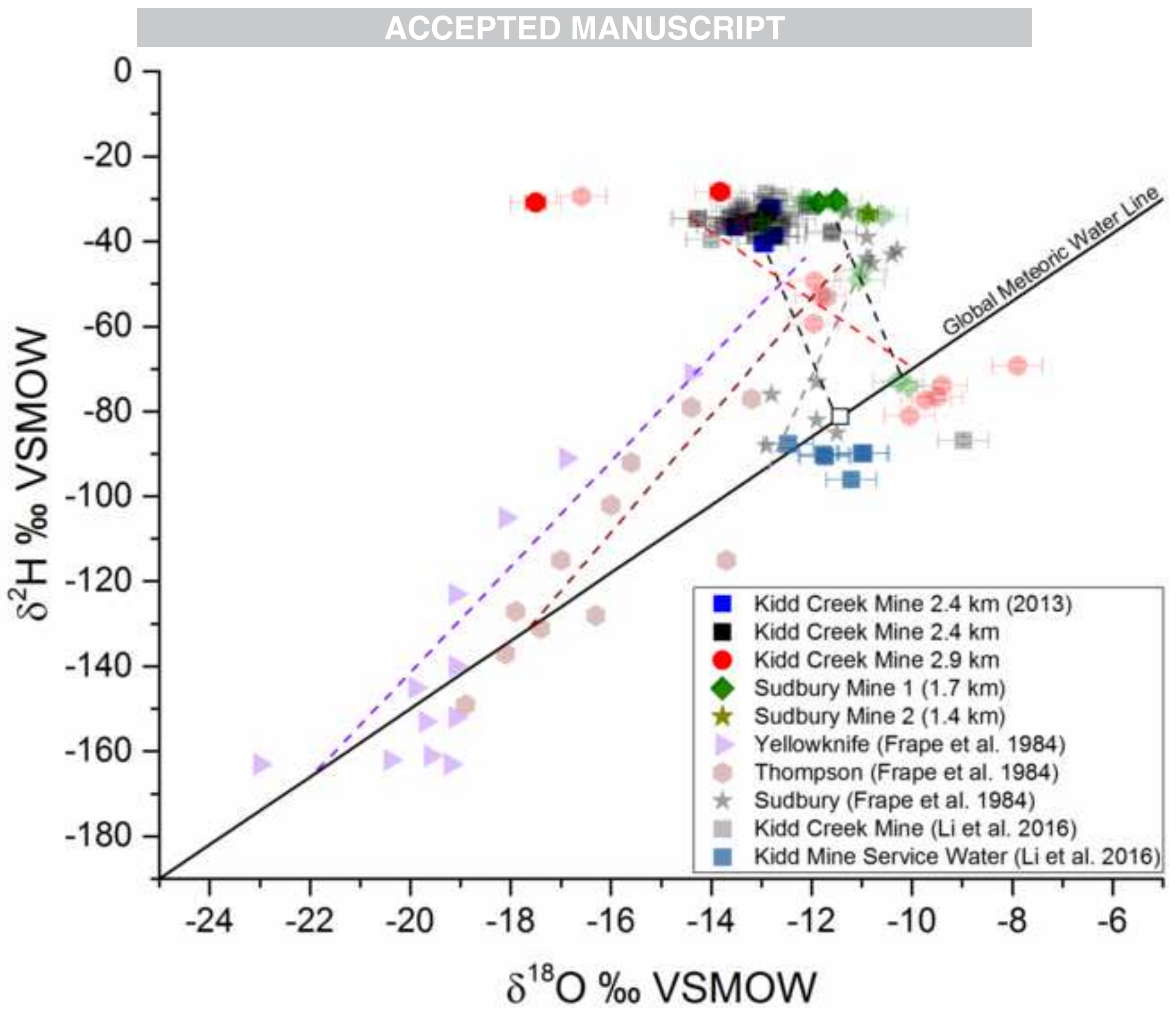

